\title{
A Fosmid Pool-Based Next Generation Sequencing Approach to Haplotype-Resolve Whole Genomes
}

\author{
Eun-Kyung Suk, Sabrina Schulz, Birgit Mentrup, Thomas Huebsch, \\ Jorge Duitama, and Margret R. Hoehe
}

\begin{abstract}
Haplotype resolution of human genomes is essential to describe and interpret genetic variation and its impact on biology and disease. Our approach to haplotyping relies on converting genomic DNA into a fosmid library, which represents the entire diploid genome as a collection of haploid DNA clones of $\sim 40 \mathrm{~kb}$ in size. These can be partitioned into pools such that the probability that the same pool contains both parental haplotypes is reduced to $\sim 1 \%$. This is the key principle of this method, allowing entire pools of fosmids to be massively parallel sequenced, yielding haploid sequence output. Here, we present a detailed protocol for fosmid pool-based next generation sequencing to haplotype-resolve whole genomes including the following steps: (1) generation of high molecular weight DNA fragments of $\sim 40 \mathrm{~kb}$ in size from genomic DNA; (2) fosmid cloning and partitioning into 96-well plates; (3) barcoded sequencing library preparation from fosmid pools for next generation sequencing; and (4) computational analysis of fosmid sequences and assembly into contiguous haploid sequences.

This method can be used in combination with, but also without, whole genome shotgun sequencing to extensively resolve heterozygous SNPs and structural variants within genomic regions, resulting in haploid contigs of several hundred $\mathrm{kb}$ up to several $\mathrm{Mb}$. This method has a broad range of applications including population and ancestry genetics, the clinical interpretation of mutations in personal genomes, the analysis of cancer genomes and highly complex disease gene regions such as MHC. Moreover, haplotyperesolved genome sequencing allows description and interpretation of the diploid nature of genome biology, for example through the analysis of haploid gene forms and allele-specific phenomena. Application of this method has enabled the production of most of the molecular haplotype-resolved genomes reported to date.
\end{abstract}

Key words Haplotype-resolving genomes, Molecular haplotypes, Phasing, Clone-based haplotyping, Fosmid library, Fosmid pools, Fosmids, Next generation sequencing, Haplotype assembly, Phasing algorithm

\section{Introduction}

Human genomes are diploid by nature. Thus, to fully understand human biology and link genetic variation to gene function and phenotype, it is essential to determine both parental sequences of an individual genome independently [1,2]. Present technologies, 
however, routinely read out "mixed diploid" sequences. Therefore, they cannot distinguish between the unique combinations of variants on each of the two chromosomal homologues, the haplotypes. Over the past few years, a number of experimental methods to haplotype-resolve genomes have been developed. Among those, clone-based haplotyping, in particular fosmid pool-based next generation sequencing (NGS), has enabled phasing by far the largest number of genomes to date, over 30 [3-9]. Here, we present the principle and concrete steps of this method.

The key principle is to convert human genomic DNA into a library of fosmids, haploid DNA fragments $\sim 40$ kilobases $(\mathrm{kb})$ in size, and partition this library into pools of fosmids such that the probability that both parental haplotypes co-occur is reduced to $\sim 1 \%$ [10]. Thus, multiple pools can be massively parallel sequenced to generate redundant coverage of both haploid genomes of an individual. In our original report introducing this principle [10], we have established "haploid clone pools" of $\sim 5000$ fosmids, random mixtures of DNA fragments representing $~ 5 \%$ of a haploid genome. These result from partitioning a library of $\sim 1.44 \times 10^{6}$ fosmid clones, ensuring $7 \times$ coverage of each haploid genome, into $3 \times 96$-well plates. In order to increase the throughput, we have chosen to combine these plates into one 96-well plate, each well containing a super-pool of $\sim 15,000$ fosmids. These super-pools are barcoded and subjected to NGS. Analysis of the NGS data showed that only $1.31 \%$ of SNP calls, on average, were heterozygous per super-pool, confirming that the method works as expected [3]. To estimate the number of super-pools necessary to be sequenced in order to reach a sufficient coverage level, simulation studies were performed. Accordingly, 40 pools were estimated to result in an average haploid read coverage of $\sim 12 \times$ (diploid read coverage of $\sim 24 \times$ ) and $85 \%$ of heterozygous SNPs phased; 48 pools were required to achieve a read coverage of $14.5 \times$ and $\sim 29 \times$, respectively, and $92 \%$ of SNPs phased.

In the molecular genetics part of our protocol, we describe the following steps (overview in Fig. 1): (1) Extraction of high molecular weight (HMW) genomic DNA (gDNA), mechanical shearing, and gel-based selection of DNA fragments of $\sim 40 \mathrm{~kb}$ in size; (2) ligation of size-selected fragments into pEpiFos vector; (3) phage packaging and mass transfection of $E$. Coli to obtain a total of $1.44 \times 10^{6}$ fosmid clones; (4) partitioning of these fosmid clones into $3 \times 96$ deep well plates to generate pools of $\sim 5000$ fosmids and amplifying those in liquid culture; (5) combining the $3 \times 96$ well plates to generate super-pools of 15,000 fosmid clones; (6) amplification of fosmid clones per well on agar plates; (7) isolation of fosmid DNA from amplified clones; (8) preparation of barcoded sequencing libraries per super-pool, and (9) processing them for NGS. We also indicate where the protocol can be adapted to newer sequencing platforms, so that it is clear which steps to modify. This 


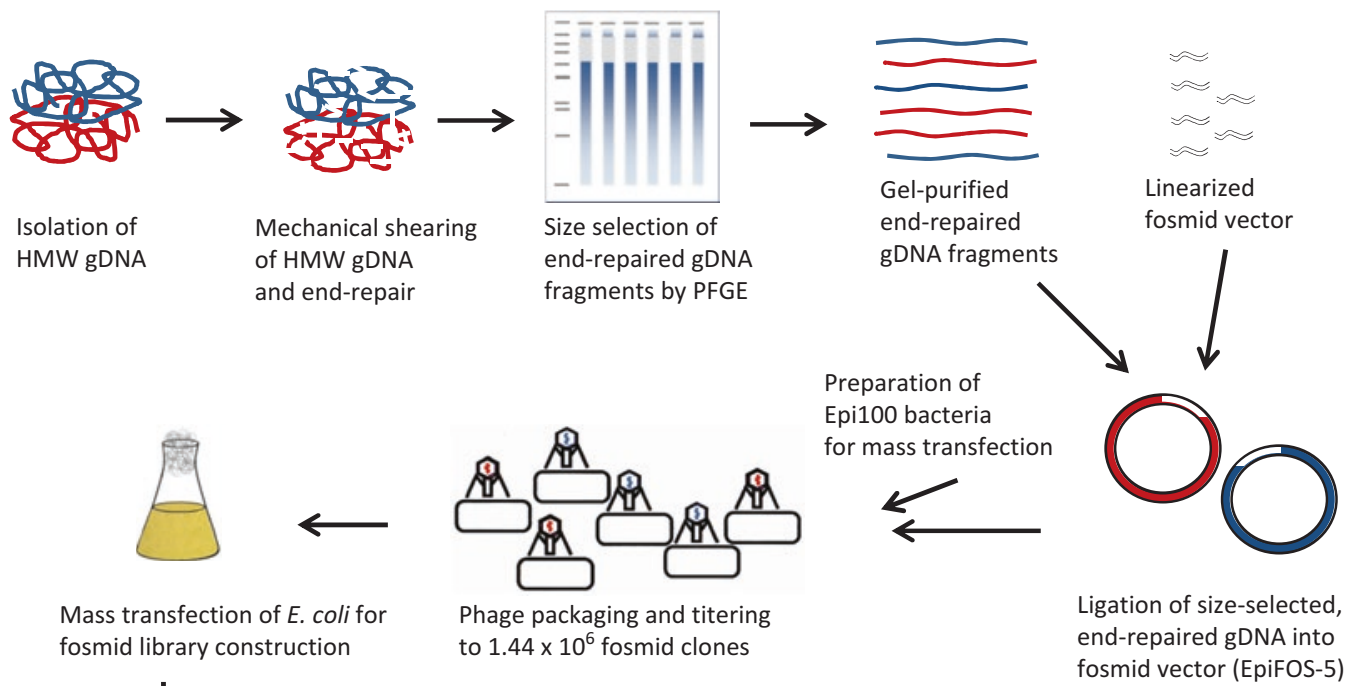

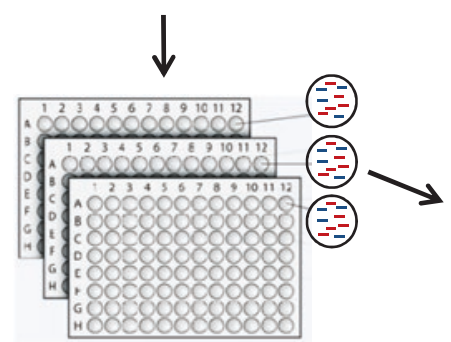

Partitioning fosmid clones into pools of $\sim 5,000$ per well, $3 \times 96$ deep well plates, amplification of fosmid library

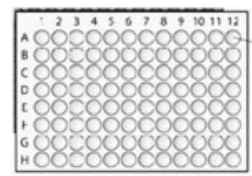

Combining 3 x 96-well plates into one 96-well plate $->$ super-pools of $\sim 15,000$ fosmid clones
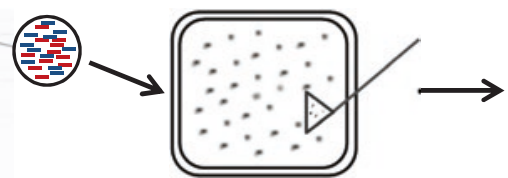

Amplification of $\sim 15,000$ fosmid clones per well on agar plates

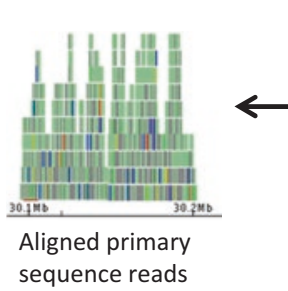

$\downarrow$

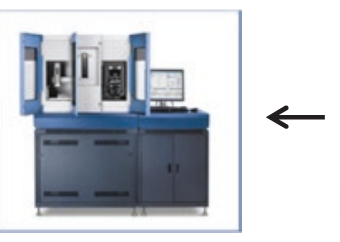

Next Generation Sequencing of barcoded fosmid super-pools

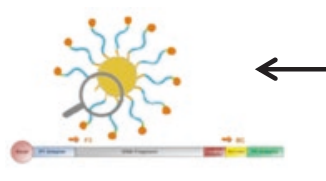

Preparation of barcoded libraries for Next Generation Sequencing
Preparation of separate barcoded fragment or mate-pair sequencing libraries for each super-pool

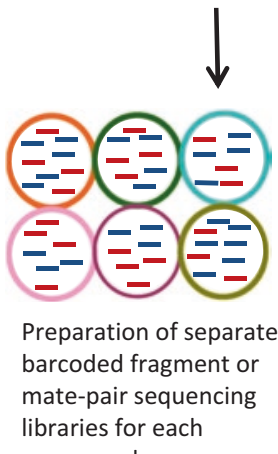

Isolation of fosmid clone DNA from super-pool

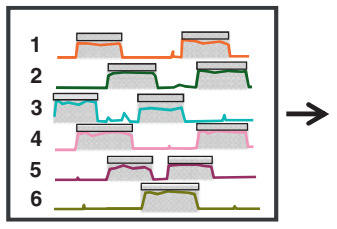

Fosmid detection per super-pool

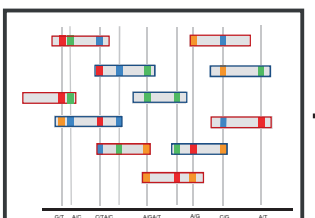

Calling variants and identification of heterozygous sites

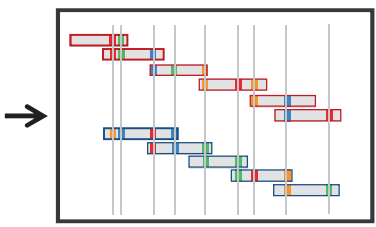

Tiling fosmids into haplotype sequences by allelic identity in regions of overlap

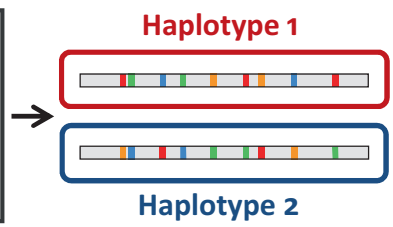

Haplotype 2

Fig. 1 Overview of fosmid pool-based Next Generation Sequencing method to haplotype-resolve whole genomes. The principle and molecular genetics and computational key steps of this method, as applied to haplotype-resolving one individual human genome, are shown 
protocol can be complemented by any routine protocol for whole genome shotgun sequencing (WGS), as we have done to generate our first haplotype-resolved genome, "Max Planck One" (MPl) [3]. This will add to the quality of heterozygote detection and help to resolve larger structural variants. Successive production of a set of 12 genomes has shown that assembly of haplotype contigs solely from fosmid pool-based NGS is feasible [9].

In the computational part of our protocol, we describe the steps involved in assembling a haplotype-resolved genome from the sequence read output in a user-oriented mode, providing downloadable algorithms and scripts. In particular, we make our specifically designed heuristic algorithm "ReFHap" [11] available, which has proven to be particularly efficient in terms of computing time and represents an optimal compromise between accuracy, completeness, and computational resources [5]. Our computational tools should be usable by any scientist with experience in NGS data analysis. Haplotype assembly includes the following steps (see Fig. 6 in the bioinformatics part): (1) alignment of fosmid pool sequence reads and sorting these alignments per pool; (2) merging sorted alignments to detect phase-informative, heterozygous variants; ( 3 ) fosmid detection and allele calling per pool; and (4) phasing by the use of ReFHap to generate haplotype contigs of phased variants per chromosome.

Our method was empirically corroborated by application to haplotyping HapMap trio child NAl2878 [5]. For this sample, whole genome sequencing of the family trio had resulted in the resolution of $\sim 80 \%$ of all heterozygous positions [12]. Where comparable, the trio-based and molecular phasing data were entirely identical, showing that fosmid pool-based haplotyping can produce highly accurate results, even at low coverage. Our method, however, allowed resolution of a much higher number of heterozygous SNPs, $\sim 98 \%$ in total, highlighting the power of our approach. Moreover, our method enabled generation of the most comprehensively haplotype-resolved human genome to date, MPI, with over $99 \%$ of all heterozygous SNPs and virtually all individual and rare SNPs phased into long haplotype blocks with an N50 of $\sim 1$ Megabase $(\mathrm{Mb})$, i.e., $50 \%$ of the haplotype-resolved sequence were within blocks of at least $\sim 1 \mathrm{Mb}$. The maximum block length achieved was $\sim 6.3 \mathrm{Mb}$ [3]. Finally, we have applied our protocol to phase an entire set of 16 human genomes [9], equivalent to about half of the published production of clone pool-based haplotyperesolved genomes.

In sum, haplotype-resolved genome sequencing is applicable to a broad range of scenarios, including population and anthropological genetics and the analysis of human diseases, for example the determination of the molecular haplotypes underlying highly variable and complex disease gene regions such as MHC, or GWAS regions. Moreover, knowledge of phase is critical for clinical 
interpretation of mutations such as compound heterozygosity or pharmacogenetically relevant variants. The same is true for the accurate and actionable description and interpretation of personal genomes as a whole. Finally, haplotype-resolved genome sequencing provides key information on genome function, for example through resolving haploid gene forms and their regulatory environments, and allele-specific phenomena in general. These include gene expression, the regulation of transcription, methylation, and other epigenetic mechanisms.

\section{Materials}

\subsection{Fosmid Library Construction}

2.1.1 High Molecular Weight (HMW) Genomic DNA (gDNA) Isolation
2.1.2 Mechanical Shearing of HMW gDNA and End-Repair
1. DNA Extraction Kit for HMW gDNA (Stratagene, Cat. Nr. 200600).

2. Centrifuge $(12,500 \times g)$ for $15 \mathrm{ml} / 50 \mathrm{ml}$ tubes.

3. Centrifuge (refrigerated, $14,000 \times g$ ) for $1.5 / 2.0 \mathrm{ml}$ tubes and 96-well plates.

4. Shaking Water bath.

5. Nanodrop ND100.

6. Rotating tube roller.

7. $50 \mathrm{ml}$ reaction tubes.

8. $1.5 / 2 \mathrm{ml}$ reaction tubes.

9. Pipettors and large-bore pipet tips.

10. Sterile glass rod.

11. Absolute EtOH p.A.

12. $70 \% \mathrm{EtOH}$.

13. TE buffer: 10 mM Tris-HCl (pH 7.5), 1 mM EDTA.

14. Pulsed Field Gel Electrophoresis System (CHEF DR II).

15. Ultrapure Low Melting Point Agarose (Thermo Fisher).

16. $10 \times$ TBE: [ $890 \mathrm{mM}$ Tris, $890 \mathrm{mM}$ Boric acid, $20 \mathrm{mM}$ EDTA $(\mathrm{pH} \mathrm{8.0)}$ ]; 0.5× TBE.

17. Lambda DNA-Mono Cut Mix DNA Ladder (NEB).

18. Loading dye.

19. Ethidium bromide.

20. UV-illuminator.

1. HydroShear shearing device (Digilab Genomic Solutions).

2. Sterile water.

3. Sterile disposable $1 \mathrm{ml}$ syringes, $23 \mathrm{G} \times 1^{1 / 4}$ injection needle.

4. Agarose gel electrophoresis system.

5. $100 \%$ Isopropanol p.A. 


\subsubsection{Size Selection of End-Repaired gDNA} Fragments by PFGE
6. TE buffer: $10 \mathrm{mM}$ Tris- $\mathrm{HCl}(\mathrm{pH} 7.5), 1$ mM EDTA.

7. EpiFOS Fosmid Library Production Kit (Epicentre, Cat. No. FOS0901).

8. $1.5 \mathrm{ml}$ reaction tubes.

9. Thermomixer.

1. Pulsed Field Gel Electrophoresis System (CHEF DR II).

2. $1 \%$ Low melting agarose.

3. $0.5 \times \mathrm{TBE}$.

4. $6 \times$ Loading Dye.

5. Lambda DNA-Mono Cut Mix DNA Ladder (NEB).

6. Sterile water.

7. Gel chamber ( $14 \mathrm{~cm}$ wide, $13 \mathrm{~cm}$ long) with preparative comb (4 wells; $1.5 \mathrm{~mm}$ thick, $27 \mathrm{~mm}$ width, $14 \mathrm{~mm}$ length, $200 \mu \mathrm{l}$ volume/well).

8. SYBR $^{\circledR}$ Gold Nucleic Acid Gel Stain 10,000× (Molecular Probes).

9. Dark Reader Transilluminator (e.g., Clare Chemical Lab) or Safe Imager Blue Light Transilluminator (Molecular Probes).

10. Razor blade (sterile).

11. Gelase enzyme (l $U / \mu l)$ (Epicentre).

12. Thermomixer.

13. Ice bath.

14. $1.5 \mathrm{ml}$ reaction tubes.

15. Centrifuge (refrigerated, $14,000 \times g$ ) for $1.5 / 2.0 \mathrm{ml}$ tubes.

16. $3 \mathrm{M}$ Sodium acetate $(\mathrm{pH} 7)$.

17. $100 \%$ Isopropanol p.A.

18. $70 \% \mathrm{EtOH}$.

19. TE buffer: 10 mM Tris- $\mathrm{HCl}(\mathrm{pH} 7.5), 1$ mM EDTA.

20. $0.8 \%$ agarose gel.

21. $0.5 \times$ TBE.

22. Fosmid Control (FC) DNA (included in EpiFOS Fosmid Library Production Kit).

23. Ethidium bromide.

24. UV-illuminator.

25. Aluminum foil.

1. EPI100 bacteria (included in EpiFOS Fosmid Library Production Kit).

2. $10 \mathrm{~cm}$ petri dishes.

3. LB broth: $10 \mathrm{~g} / 1$ Bacto-Tryptone, $10 \mathrm{~g} / 1 \mathrm{NaCl}, 5 \mathrm{~g} / 1$ Yeast Extract. 
2.1.5 Ligation of SizeSelected gDNA into pEpiFOS-Vector, Phage Packaging, and Testing Titer

2.1.6 Mass Transfection of E. Coli

2.1.7 Partitioning Fosmid Clones into Pools and Amplification of Fosmid Library
4. LB agar: LB-Broth, 15 g/l Bacto-Agar.

5. $10 \mathrm{mM} \mathrm{MgSO}_{4}$.

6. Autoclave.

7. Incubator $\left(37^{\circ} \mathrm{C}\right)$.

8. $50 \mathrm{ml}$ Erlenmeyer flask.

9. UV-Spectrophotometer (Eppendorf).

1. Fast-Link Ligase and Buffer (included in EpiFOS Fosmid Library Production Kit).

2. $200 \mu \mathrm{l}$ Microtubes.

3. $1.5 \mathrm{ml}$ reaction tubes.

4. Thermomixer.

5. Sterile water.

6. Ice bath.

7. MaxPlax-Lambda Packaging Extract (included in EpiFOS Fosmid Library Production Kit).

8. Chloroform.

9. Epil00 bacteria (included in EpiFOS Fosmid Library Production Kit).

10. LB-Agar plates with $12.5 \mu \mathrm{g} / \mathrm{ml}$ chloramphenicol $(10 \mathrm{~cm}$ petri dishes).

11. Incubator $\left(37^{\circ} \mathrm{C}\right)$.

1. Laminar flow hood.

2. LB broth with $10 \mathrm{mM} \mathrm{MgSO}_{4}$ and $12.5 \mu \mathrm{g} / \mathrm{ml}$ Cloramphenicol.

3. 96-deep well plates.

4. Erlenmeyer flask.

5. EPI100 bacteria (included in EpiFOS Fosmid Library Production Kit).

6. Shaking incubator $\left(37^{\circ} \mathrm{C}\right)$.

1. 96-deep well plates.

2. LB broth.

3. Multipette (Eppendorf).

4. Breathable seal.

5. Shaking incubator $\left(37^{\circ} \mathrm{C}\right)$.

6. LB Agar plates with $12.5 \mu \mathrm{g} / \mathrm{ml}$ Chloramphenicol.

7. Sterile glycerol $(90 \%)$.

8. Eight-channel pipette.

9. Aluminum foil.

10. $-80{ }^{\circ} \mathrm{C}$ freezer. 
2.2 Isolation of Fosmid DNA from Fosmid Clone Pools

2.2.1 Plating and Scraping Fosmid Super-Pools

2.2.2 Extraction of Fosmid Super-Pool DNA
1. Large LB agar plates $(22 \mathrm{~cm} \times 22 \mathrm{~cm})$ with $12.5 \mu \mathrm{g} / \mathrm{ml}$ Chloramphenicol.

2. LB broth, and LB broth with $12.5 \mu \mathrm{g} / \mathrm{ml}$ Cloramphenicol.

3. Inoculating loop.

4. Drigalski spatula.

5. $50 \mathrm{ml}$ reaction tubes (Falcon).

1. Ice bath.

2. Centrifuge $(12,500 \times g)$ for $15 \mathrm{ml} / 50 \mathrm{ml}$ Falcon tubes.

3. Centrifuge (refrigerated, $12,500 \times g$ ) for $1.5 / 2.0 \mathrm{ml}$ tubes and 96-well plates.

4. QIAGEN Large-Construct Kit.

5. Fluted filters.

6. QIAGEN-tip 500 (to be purchased in addition, 2 per extraction required).

7. ATP disodium salt (AppliChem).

8. Water bath.

9. $100 \%$ Isopropanol p.A.

10. $70 \% \mathrm{EtOH}$.

11. $1.5 \mathrm{ml}$ reaction tubes.

12. TE buffer: $10 \mathrm{mM}$ Tris-HCl (pH 7.5), 1 mM EDTA.

13. Agarose gel electrophoresis system.

2.3 Fosmid PoolBased Next Generation Sequencing Library Preparation

2.3.1 Barcoded Preparation of Fragment Libraries
1. Covaris S2 Sonicator (Covaris).

2. Covaris microTUBEs (Covaris).

3. Low TE buffer (Applied Biosystems).

4. Covaris G7 adaptor (Covaris).

5. Lonza Flash Gel System (Lonza).

6. $2.2 \%$ Lonza FlashGel Cassette (Lonza).

7. GeneRuler Low Range DNA Ladder, ready-to-use with 6x Orange DNA Loading Dye (Fermentas).

8. MinElute Gel Extraction Kit (QIAGEN).

9. $1.5 \mathrm{ml}$ DNA LoBind tubes (Eppendorf).

10. End-It DNA End-Repair Kit (Epicentre).

11. Thermoshaker.

12. Qubit Fluorometric Quantitation (Thermo Scientific).

13. Qubit dsDNA HS Assay Kit (Thermo Scientific).

14. 4\% Reliant NuSieve 3:1 agarose gel (Lonza).

15. UV Multibright Transilluminator (Intas). 
16. SOLiD Fragment Library Oligo Kit (Applied Biosystems).

17. Quick Ligation Kit (NEB).

18. MinElute Reaction Cleanup Kit (QIAGEN).

19. Gel electrophoresis system (Bio-Rad).

20. Ethidium bromide (AppliChem).

21. DNA Polymerase I (E. coli) $(10 \mathrm{U} / \mu \mathrm{l})(\mathrm{NEB})$.

22. $100 \mathrm{mM}$ dNTP-Mix (GeneAmp).

23. Microcentrifuge 5417R (Eppendorf).

24. Thermomixer.

2.3.2 Barcoded Preparation of Mate-Paired Libraries
1. SOLiD Mate-Paired Library Oligo Kit (Applied Biosystems).

2. HydroShear (Genomic Solutions, Inc.).

3. HydroShear Standard Shearing Assembly 1-5 kb (Genomic Solutions, Inc.).

4. QIAquick Gel Extraction Kit (QIAGEN).

5. End-It DNA End-Repair Kit (Epicentre).

6. $500 \mathrm{mM}$ EDTA.

7. Quick Ligation Kit (NEB).

8. Microcentrifuge 5417R (Eppendorf).

9. 10× TAE (Applied Biosystems).

10. Agarose-LE (Applied Biosystems).

11. Gel electrophoresis system (any supplier).

12. Ethidium bromide (AppliChem).

13. $1 \mathrm{~Kb}$ DNA Ladder (Invitrogen).

14. Gel imaging system (any supplier).

15. Plasmid-Safe ATP-Dependent DNase (Epicentre).

16. DNA Polymerase I (E. coli) $(10 \mathrm{U} / \mu \mathrm{l})(\mathrm{NEB})$.

17. $100 \mathrm{mM}$ dNTP Mix (GeneAmp).

18. T7 Exonuclease $(10 \mathrm{U} / \mu \mathrm{l})(\mathrm{NEB})$.

19. SI Nuclease (400-1500 U/ $\mu \mathrm{l})$ (Invitrogen).

20. 3 M Sodium chloride, $5 \mathrm{M}$ Sodium chloride.

21. Tris- $\mathrm{HCl}(500 \mathrm{mM}, \mathrm{pH} 7.5)$.

22. I M Magnesium chloride (Ambion).

23. Streptavidin Dynabeads, Dynal MyOne Cl (Thermo Fisher Scientific).

24. SOLiD Buffer Kit (including $1 \times$ Bead Wash Buffer, $1 \times$ Bind $\&$ Wash Buffer, $1 \times$ Low Salt Binding Buffer, Low TE Buffer, $1 \times$ TEX Buffer, 2-Butanol) (Applied Biosystems).

25. $100 \times$ BSA (NEB). 
2.3.3 Large-Scale PCR of Fragment and MatePaired Libraries
2.3.4 Preparation of Fragment and MatePaired Sequencing Libraries for Emulsion PCR

\subsection{Processing} Next Generation Sequencing Libraries for Instrument Run

2.4.1 Emulsion PCR
26. Six Tube Magnetic Stand (Applied Biosystems).

27. Vortexer (any supplier).

28. Rotator for 1.5-2.0 ml tubes (any supplier).

1. PCR SuperMix (Invitrogen).

2. Cloned Pfu polymerase $(2.5 \mathrm{U} / \mu \mathrm{L})$ (Stratagene).

3. $4 \%$ Reliant NuSieve 3:1 agarose gel (Lonza).

4. GeneRuler Low Range DNA Ladder, ready-to-use with 6x Orange DNA Loading Dye (Fermentas).

5. MinElute Reaction Cleanup Kit (QIAGEN).

6. QIAquick Gel Extraction Kit (QIAGEN).

7. Gel electrophoresis system (any supplier).

8. Gel imaging system (any supplier).

9. SOLiD Mate-Paired Library Oligo Kit (Applied Biosystems).

10. SOLiD Fragment Library Oligo Kit (Applied Biosystems).

11. 96-Well GeneAmp PCR System 9700 (Applied Biosystems).

12. Lonza Flash Gel System (Lonza).

13. $2.2 \%$ Lonza FlashGel Cassette (Lonza).

14. Ethidium bromide (AppliChem).

15. $15 \mathrm{ml}$ conical tubes (Falcon).

16. Microcentrifuge $(12,500 \times g)$.

17. Qubit Fluorometric Quantitation (Thermo Scientific).

18. Qubit dsDNA HS Assay Kit (Thermo Scientific).

19. $1.5 \mathrm{ml}$ DNA LoBind tubes (Eppendorf).

20. Six Tube Magnetic Stand (Applied Biosystems).

1. Qubit Fluorometric Quantitation (Thermo Scientific).

2. Qubit dsDNA HS Assay Kit (Thermo Scientific).

3. SOLiD Buffer Kit (including $1 \times$ Bead Wash Buffer, $1 \times$ Bind $\&$ Wash Buffer, $1 \times$ Low Salt Binding Buffer, Low TE Buffer, $1 \times$ TEX Buffer, 2-Butanol) (Applied Biosystems).

1. 96-Well GeneAmp PCR System 9700 (Applied Biosystems).

2. SOLiD Buffer Kit (Applied Biosystems).

3. SOLiD ePCR Kit (Applied Biosystems).

4. $1 \mathrm{ml}$ glass pipet (any supplier).

5. $5 \mathrm{ml}$ glass pipet (any supplier).

6. ULTRA-TURRAX Tube Drive (IKA).

7. SOLiD ePCR Tubes and Caps (IKA). 
8. Covaris S2 Sonicator (Covaris).

9. Covaris-2 Series Machine Holder for 1.5-ml microcentrifuge tube (Covaris).

10. Covaris-2 Series Machine Holder for $0.65-\mathrm{ml}$ microcentrifuge tube (Covaris).

11. $15 \mathrm{ml}$ tube (Falcon).

12. $50 \mathrm{ml}$ tube (Falcon).

13. Vortexer (any supplier).

14. Semi-automated Xstream pipettor (Eppendorf).

15. Repeater plus pipette (Eppendorf).

16. MicroAmp Optical 96-Well Reaction Plates (Applied Biosystems).

17. MicroAmp Optical Adhesive Film (Applied Biosystems).

18. Six Tube Magnetic Stand (Applied Biosystems).

19. NanoDrop ND1000 Spectrophotometer (Thermo Scientific).

20. Nuclease-free water.

2.4.2 Breaking the Emulsion PCR

2.4.3 Enrichment of Templated Beads
1. SOLiD Buffer Kit (Applied Biosystems).

2. Repeater plus pipette (Eppendorf).

3. $50 \mathrm{ml}$ tube (Falcon).

4. SOLiD Emulsion Collection Tray Kit (Applied Biosystems).

5. Fume hood (any supplier).

6. NanoDrop ND1000 Spectrophotometer (Thermo Scientific).

7. Six Tube Magnetic Stand (Applied Biosystems).

8. $1.5 \mathrm{ml}$ LoBind Tubes (Eppendorf).

1. SOLiD Bead Enrichment Kit (Applied Biosystems).

2. SOLiD Buffer Kit (Applied Biosystems).

3. Microcentrifuge $(12,500 \times g)$.

4. $15 \mathrm{ml}$ tubes (Falcon).

5. Six Tube Magnetic Stand (Applied Biosystems).

6. Covaris S2 Sonicator (Covaris).

7. Covaris-2 Series Machine Holder for 1.5-ml microcentrifuge tube (Covaris).

8. Covaris-2 Series Machine Holder for 0.65- $\mathrm{ml}$ microcentrifuge tube (Covaris).

9. $0.5 \mathrm{ml}$ LoBind Tubes (Eppendorf).

10. $1.5 \mathrm{ml}$ LoBind Tubes (Eppendorf).

11. $2.0 \mathrm{ml}$ LoBind Tubes (Eppendorf). 


\subsection{4 $3^{\prime}$-End Modification of Enriched Templated Beads}

2.4.5 Bead Deposition on SOLiD Sequencing Slide and Instrument Run

\subsection{Computational Analysis of Fosmid Sequences and Haplotype Assembly}

\subsubsection{Hardware}

Requirements

\subsubsection{Software Requirements}

1. Six Tube Magnetic Stand (Applied Biosystems).

2. SOLiD Buffer Kit (Applied Biosystems).

3. Covaris S2 Sonicator (Covaris).

4. Covaris-2 Series Machine Holder for 1.5-ml microcentrifuge tube (Covaris).

5. SOLiD Bead Deposition Kit (Applied Biosystems).

6. $1.5 \mathrm{ml}$ LoBind Tubes (Eppendorf).

7. NanoDrop ND1000 Spectrophotometer (Thermo Scientific).

1. SOLiD Bead Deposition Kit (Applied Biosystems).

2. Covaris S2 Sonicator (Covaris).

3. $1.5 \mathrm{ml}$ LoBind Tubes (Eppendorf).

4. Six Tube Magnetic Stand (Applied Biosystems).

5. Covaris-2 Series Machine Holder for 1.5-ml microcentrifuge tube (Covaris).

6. SOLiD Slide Kit (Applied Biosystems).

7. SOLiD Bead Deposition Kit (Applied Biosystems).

8. SOLiD Fragment Library Sequencing Kit (Applied Biosystems).

9. SOLiD Mate-Paired Library Sequencing Kit (Applied Biosystems).

10. SOLiD Instrument Buffer Kit (Applied Biosystems).

11. SOLiD Deposition Chamber 1, 4, 8 well (Applied Biosystems).

The computational requirements for primary and secondary sequence analysis include high-end computing servers with $>1$ Terabyte (TB) disk space (RAID system) and $>32$ Gigabyte (GB) Memory (RAM), and $>4$ CPU cores per server or cluster node.

The following list of software tools is used at different (generally successive) stages of this process:

For SOLiD NGS Analysis: BioScope ${ }^{\mathrm{TM}}$ Software

For other NGS systems such as Illumina:

Bwa [13]: http://bio-bwa.sourceforge.net/

Bowtie2 [14]: http://bowtie-bio.sourceforge.net/bowtie2/ manual.shtml

Picard: http://broadinstitute.github.io/picard/

NGSEP [15]: http://sourceforge.net/projects/ngsep/

GATK [16]: https://www.broadinstitute.org/gatk/

Samtools [17]: http://samtools.sourceforge.net/

Fosmid detector [3] and ReFHap [5, 11]: http://www.molgen. mpg.de/ genetic-variation/SIH/Data/algorithms. This address includes a README.txt file with detailed instructions to run both the fosmid detector and ReFHap. 
3 Methods

\subsection{Fosmid Library Construction}

3.1.1 High Molecular Weight Genomic DNA Isolation
The following procedures apply to haplotype-resolving one individual genome.

To establish a high quality individual fosmid library, two kits proved to work well and efficiently in conjunction, the DNA Extraction Kit from Stratagene and the EpiFOS Fosmid Library Production Kit from Epicentre. The first one, specifically, provides three solutions almost ready to use, and a protease mixture to digest cellular proteins and RNase to eliminate RNA. Its protocol is applicable to isolate HMW gDNA from blood, whole tissue, and cultured cells. The second kit can be applied to establish a fosmid library from sheared gDNA, and provides all components and reagents required to end-repair and ligate the sheared gDNA into a single copy fosmid vector, phage-package the fosmid clone DNA, and transfect $E$. coli cells ( see Note $\mathbf{1}$ ).

The preparation of fosmid clones requires very high quality HMW gDNA.

1. Start with $8 \mathrm{ml}$ EDTA blood in a $50 \mathrm{ml}$ reaction tube for the extraction of a total of 40-50 $\mu \mathrm{g}$ HMW gDNA per individual sample. Add $42 \mathrm{ml} \mathrm{l} \times$ Solution 1 according to the manufacturer's protocol, and incubate the sample on ice for $2 \mathrm{~min}$, followed by spinning it at $350 \times g$ and $4{ }^{\circ} \mathrm{C}$ for $15 \mathrm{~min}$. Discard the supernatant carefully, because the pellet is very instable. Resuspend the pellet in $11 \mathrm{ml}$ of Solution 2, add $5 \mu$ pronase $(225 \mathrm{mg} / \mathrm{ml})$ to a final concentration of $100 \mu \mathrm{g} / \mathrm{ml}$ and incubate the sample in a shaking water bath for $1 \mathrm{~h}$ at $60^{\circ} \mathrm{C}$. Transfer it on ice for $10 \mathrm{~min}$, add $4 \mathrm{ml}$ of Solution 3, and invert the tube several times (see Note 2). Incubate the sample for 5 more min on ice to precipitate the cellular proteins. Spin the tube at $2000 \times g$ and $4{ }^{\circ} \mathrm{C}$ for $15 \mathrm{~min}$ and transfer the supernatant to a sterile $50 \mathrm{ml}$ tube by using a large-bore pipet tip (see Note 3).

2. For RNA digestion, add RNase $(10 \mathrm{mg} / \mathrm{ml})$ to a final concentration of $20 \mu \mathrm{g} / \mathrm{ml}$ and incubate the sample in a water bath for $15 \mathrm{~min}$ at $37^{\circ} \mathrm{C}$.

3. The HMW gDNA can be precipitated after adding two volumes of absolute $\mathrm{EtOH}$ and gently inverting the tube. Use a sterile glass rod to spool the gDNA and rinse it with $70 \%$ EtOH. Dry the spooled DNA, transfer it into a sterile $50 \mathrm{ml}$ tube, and carefully resuspend it in $500 \mu \mathrm{l}$ pre-warmed TE buffer (see Note 4). Avoid any vortexing or pipetting, which might degrade the HMW gDNA. 
3.1.2 Mechanical Shearing of HMW gDNA and End-Repair
3.1.3 Size Selection of End-Repaired gDNA Fragments by PFGE
4. Dissolve the pellet on a slowly rotating tube roller at $4{ }^{\circ} \mathrm{C}$ (see Note 5). Calculate the yield and concentration of your sample by measuring the $\mathrm{OD}_{260}$. Store the DNA at $4{ }^{\circ} \mathrm{C}$.

5. Control the quality of the extracted HMW gDNA: run a Pulsed Field Gel Electrophoresis (PFGE) with a $1 \%$ agarose gel in $0.5 \times \mathrm{TBE}$, load $3 \mu \mathrm{l}$ of the HMW gDNA, use $\lambda$ DNA-Mono Cut Mix DNA Ladder in the outer lanes as reference, run PFGE at $6 \mathrm{~V} / \mathrm{cm}$, switch time $0.2-2 \mathrm{~s}, 13-16 \mathrm{~h}$ (see Note 6).

To provide the basis for the fosmid library construction, the extracted HMW gDNA needs to be fragmented into $\sim 40 \mathrm{~kb}$ segments and end-repaired to be cloned into a fosmid vector. DNA fragments larger than $\sim 60 \mathrm{~kb}$ or smaller than $\sim 20 \mathrm{~kb}$ can prevent phage-packaging at a later stage. Moreover, the use of fragments $<20 \mathrm{~kb}$ might result in the formation of chimeric clones.

1. Dilute $8 \mu \mathrm{g}$ HMW gDNA to a final concentration of $20 \mathrm{ng} / \mu \mathrm{l}$.

2. Shear the DNA using a HydroShear shearing device; use the 4-40 kb (LARGE) shearing assembly. Since every shearing assembly has slightly different shearing properties, test different speed codes at the outset: prepare three aliquots of $8 \mu \mathrm{g}$ DNA $(400 \mu \mathrm{l})$ and test them with speed codes "16," "17," or "18," retraction speed "20," and 25 shearing cycles. Check and compare the results on an agarose gel.

3. Alternatively, if a HydroShear device is not available, the DNA can be sheared manually using a sterile $1 \mathrm{ml}$ disposable syringe with a $23 \mathrm{G} \mathrm{1} 1 \frac{1}{4}$ needle, aspirating $400 \mu \mathrm{l}$ of the diluted HMW gDNA and pulling the syringe up and down for $50 \mathrm{~s}$ (12 times) ( see Note 7).

4. After controlling the shearing results on by PFGE (see Subheading 3.1.1, step 5), precipitate the sheared DNA with isopropanol (100\%) (see Subheading 3.1.3, step 5) and resuspend the sheared gDNA in $26 \mu \mathrm{TE}$.

5. To produce blunt-end gDNA fragments, mix $4 \mu$ l End-Repair $10 \times$ Buffer, $4 \mu \mathrm{l}$ of $2.5 \mathrm{mM}$ dNTPs and $4 \mu \mathrm{l}$ of $10 \mathrm{mM}$ ATP into a $1.5 \mathrm{ml}$ tube, add $26 \mu \mathrm{l}$ of sheared gDNA and $2 \mu \mathrm{l}$ EndRepair Enzyme (final volume $40 \mu \mathrm{l}$ ), incubate the mix for $60 \mathrm{~min}$ at room temperature, and transfer the tube into a preheated thermomixer $\left(70{ }^{\circ} \mathrm{C}\right)$ for $10 \mathrm{~min}$ to inactivate the enzymes ( see Note 8).

Size-selection by PFGE is performed to guarantee suitable DNA fragments for library production.

1. Prepare a $1 \%$ low melting point (LMP) agarose gel (with $200 \mathrm{ml} 0.5 \times \mathrm{TBE}$ ), using a preparative comb with four slots (see Note 9). Mix $40 \mu \mathrm{l}$ end-repaired gDNA with $7 \mu \mathrm{l} 6 \times$ loading dye, and slowly pipet gDNA sample into one preparative 
slot. Keeping one well empty between gDNA sample and size ladder, load $1 \mu \mathrm{l} \lambda$ DNA-Mono Cut Mix DNA ladder (mixed with $1 \mu \mathrm{l} 6 \times$ loading dye and $4 \mu \mathrm{dH}_{2} \mathrm{O}$ ) on both sides of the gDNA sample. Run a PFGE at $6 \mathrm{~V} / \mathrm{cm}$; initial sweep time 0.5 ; final sweep time $2.0 \mathrm{~s}$; for $20-22 \mathrm{~h}$.

2. Use Sybr Gold Dye to stain the agarose gel to avoid the need for UV exposure. Prepare a staining solution by pipetting the $10 \mu \mathrm{l}$ Sybr Gold Stock Solution into $100 \mathrm{ml}$ of $0.5 \times$ TBE (in a $100 \mathrm{ml}$ glass flask wrapped in aluminum foil), pour the staining solution into a plastic tray, lift the gel into the staining bath, and leave for at least $30 \mathrm{~min}$ ( see Note 10).

3. Visualize stained gDNA fragments on a Dark Reader Transilluminator. Ensure that the bulk of sheared gDNA has migrated within the correct size range $(20-50 \mathrm{~kb})$. Make a hole with a pipet tip at the $30 \mathrm{~kb}$ and $48 \mathrm{~kb}$ band of the size ladder, turn off illumination, use a sterile razor blade to select sheared gDNA by making a cut parallel to the 30 and $48 \mathrm{~kb}$ size ladder band (using the holes as marks) and excising the gel pieces with size-selected DNA fragments by vertical cuts (see Fig. 2 and Note 11).

4. To recover the size-selected gDNA, warm Gelase $50 \times$ Reaction Buffer in a thermomixer at $45^{\circ} \mathrm{C}$, set a second thermomixer (or a water bath) to $70{ }^{\circ} \mathrm{C}$, push excised gel slice into a $2 \mathrm{ml}$ tared tube, and weigh the gel piece. Translate solid gel weight into volume of molten agarose ( $1 \mathrm{mg}$ of solid gel will result in $1 \mu \mathrm{l}$ molten agarose), calculate volume of $50 \times$ Gelase Buffer required to yield a $1 \times$ Buffer, and calculate Gelase enzyme units ( $1 \mathrm{U} / \mu \mathrm{l}$; $1 \mathrm{U}$ Gelase enzyme per $100 \mu \mathrm{l}$ molten agarose) needed after the subsequent step. Heat tube with weighed gel

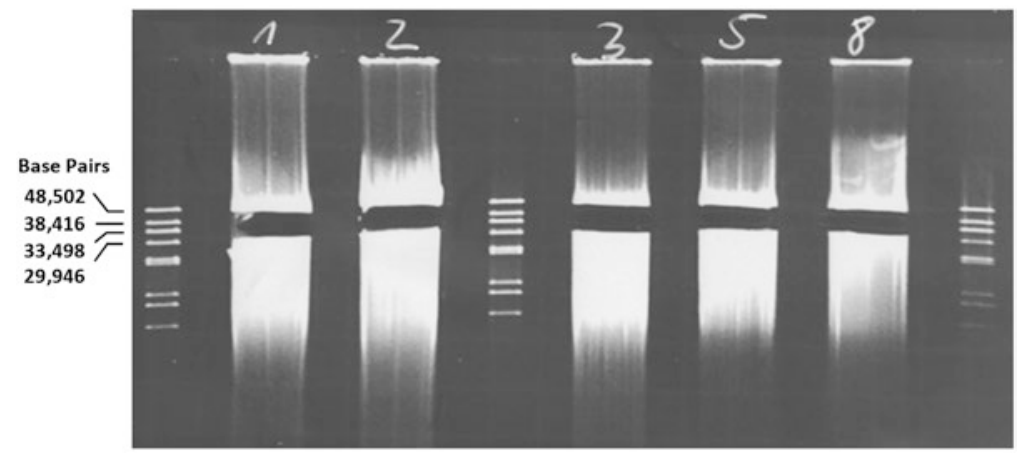

Fig. 2 Size-selection of end-repaired gDNA fragments after PFGE. Sheared gDNA from five different individuals resolved by PFGE on a $1 \%$ low melting point (LMP) agarose gel (200 ml 0.5 $\times$ TBE) together with a $\lambda$ DNA-Mono Cut Mix DNA Ladder; gel stained with Sybr Gold Dye. Gel pieces with fragments between $\sim 30$ and $48 \mathrm{~kb}$ in size were cut out 
3.1.4 Preparation of Epi100 Bacteria for Mass Transfection slices in a $70{ }^{\circ} \mathrm{C}$ thermomixer (or water bath), keep for 10-15 min until the agarose is molten, quickly transfer tubes with molten agarose to $45{ }^{\circ} \mathrm{C}$ thermomixer, add appropriate volume of pre-warmed $50 \times$ Gelase Buffer and appropriate units of Gelase enzyme, gently mix the solution, and incubate for at least $60 \mathrm{~min}$ at $45^{\circ} \mathrm{C}$. Heat inactivate Gelase enzyme at $70{ }^{\circ} \mathrm{C}$, then chill the mix for $15 \mathrm{~min}$ in an ice bath. Centrifuge the reaction mix for $20 \mathrm{~min}$ at maximum speed $(11,000 \times g)$, and transfer most of supernatant to a new $1.5 \mathrm{ml}$ tube, making sure to not aspirate the gelatinous pellet.

5. Purify size-selected gDNA after gelase digest, add $1 / 10$ volume $3 \mathrm{M}$ sodium acetate ( $\mathrm{pH} 7$ ), mix gently, add 1 volume isopropanol, gently invert the tube, leave for $10 \mathrm{~min}$ at room temperature, centrifuge for $20-30 \mathrm{~min}$ at full speed, remove supernatant and wash pellet with $1 \mathrm{ml} 70 \%$ ethanol twice, airdry pellet for $10 \mathrm{~min}$, and resuspend in $11 \mu \mathrm{TE}$.

6. To control for quality and quantity of size-selected gDNA, run an $0.8 \%$ TBE agarose gel (minigel of $7-10 \mathrm{~cm}$ length), load $1 \mu \mathrm{l}$ of size-selected gDNA, use $1 \mu \mathrm{l}$ Fosmid Control (FC) DNA from the EpiFOS Fosmid Library Production Kit (Epicentre) (size $40 \mathrm{~kb}, 100 \mathrm{ng} / \mu \mathrm{l}$ ) on both sides of the sample, additionally load $1 \mu \mathrm{l}$ each of a $1: 2$ and $1: 4$ dilution of the FC DNA, run the gel at $6 \mathrm{~V} / \mathrm{cm}$ for $40-60 \mathrm{~min}$, stain with ethidium bromide, and visualize on an UV-illuminator and check the quantity and size of the size-selected gDNA by comparing the sample to the FC DNA dilutions.

The EpiFOS Fosmid Library Production Kit (Epicentre) provides a glycerol stock of EPI100 bacteria suitable for mass transfection.

1. Use multiple $10 \mathrm{~cm}$ petri dishes, prepare LB agar [without chloramphenicol (CA)], autoclave and pour warm into dishes, and use solidified LB agar plates to streak Epil 00 plating strain (see Note 12). Incubate at $37^{\circ} \mathrm{C}$ overnight, seal and store the plate at $4{ }^{\circ} \mathrm{C}$. The day before the phage-packaging procedure, pick a single colony from the plated strain and inoculate a $50 \mathrm{ml}$ Erlenmeyer flask with fresh $\mathrm{LB}$ broth and $10 \mathrm{mM}$ $\mathrm{MgSO}_{4}$. Shake the flask overnight at $37^{\circ} \mathrm{C}$, and use $2 \mathrm{ml}$ of the overnight culture for the next step (Subheading 3.1.4, step 2). The overnight culture can be stored at $4{ }^{\circ} \mathrm{C}$ ( see Note 13).

2. On the day of phage packaging, prepare an Erlenmeyer flask with fresh $50 \mathrm{ml} \mathrm{LB}$ broth and $10 \mathrm{mM} \mathrm{MgSO}_{4}$, then inoculate with $2 \mathrm{ml}$ of the Epil 00 overnight culture from step 1; shake at $37^{\circ} \mathrm{C}$ until $\mathrm{OD}_{600}$ reaches 0.85 , measuring every $20 \mathrm{~min}$.

3. Prepare multiple LB plates with CA in $10 \mathrm{~cm}$ petri dishes; these will be used to determine the titer of packaged fosmid clones (phage particles) in Subheading 3.1.5. Seal and store LB plates at $4^{\circ} \mathrm{C}($ see Note 14$)$. 
3.1.5 Ligation of SizeSelected gDNA into EpiFOS-Vector, Phage Packaging, and Testing Titer
In order to establish an individual fosmid library that ensures a $\sim 7 x$ coverage of the haploid and $\sim 15 \times$ coverage of the diploid genome, a total of $1.44 \times 10^{6}$ fosmid clones need to be generated.

1. For the ligation reaction, combine $1 \mu$ Fast-Link Ligation 10× Buffer, $1 \mu \mathrm{l} 10 \mathrm{mM}$ ATP, $1 \mu \mathrm{l}$ pEpiFOS-Vector (500 ng), and $250 \mathrm{ng}$ of the size-selected gDNA (corresponding to a 10:1 M ratio of vector:insert) in a new $200 \mu \mathrm{l}$ microtube, add $1 \mu \mathrm{l}$ Fast-Link Ligase $(2 \mathrm{U} / \mu \mathrm{l})$ and $\mathrm{dH}_{2} \mathrm{O}$ to a final reaction volume of $10 \mu \mathrm{l}$, seal the tube and incubate the reaction for $2 \mathrm{~h}$ at room temperature, inactivate by placing micro tube at $70{ }^{\circ} \mathrm{C}$ for $10 \mathrm{~min}$. In order to control the fosmid library production procedure, prepare a control reaction, use $2.5 \mu \mathrm{l}$ of $40 \mathrm{~kb}$ FC insert DNA provided in the kit instead of size-selected gDNA. The control ligation reaction used to determine the packaging efficiency (see Subheading 3.1.5, step 3) should yield more than $1 \times 10^{7}$ colony forming units $(\mathrm{cfu}) / \mathrm{ml}$ of control insert DNA.

2. For phage packaging, thaw one tube of MaxPlax-Lambda Packaging Extract on ice, immediately transfer half of the extract $(25 \mu \mathrm{l})$ into a new $1.5 \mathrm{ml}$ tube, and store the remaining half of packaging extract at $-80{ }^{\circ} \mathrm{C}$ freezer. Add $10 \mu \mathrm{l}$ of ligated DNA and mix by pipetting the reaction repeatedly (do not introduce air bubbles), spin down the tube, and incubate the reaction mixture for $90 \mathrm{~min}$ in a thermomixer at $30^{\circ} \mathrm{C}$. Five min before the end of the incubation period, take the remaining half of the packaging extract out of the freezer and put it on ice to thaw it. Then add it to the reaction mixture and incubate the reaction again for $90 \mathrm{~min}$ at $30^{\circ} \mathrm{C}$. Finally, add $940 \mu \mathrm{l}$ Phage Dilution Buffer (PDB) to a total volume of $1 \mathrm{ml}$, mix gently, then add $25 \mu \mathrm{l}$ of chloroform to the reaction, and store at $4{ }^{\circ} \mathrm{C}$.

3. Phage titer testing: To determine the number of phage particles that contain fosmid clones, use $10 \mu \mathrm{l}$ of the $1 \mathrm{ml}$ phage packaging reaction (see step 2), add $990 \mu \mathrm{l}$ PDB to generate a $1: 10^{2}$ phage dilution, then use $100 \mu \mathrm{l}$ of the $1: 10^{2}$ dilution and $900 \mu \mathrm{l}$ of PDB to prepare a $1: 10^{3}$ dilution. Processing two dilutions in parallel is useful to be able to determine the efficiency of the phage packaging reaction as precisely as possible. Then mix $10 \mu \mathrm{l}$ of each phage dilution with $100 \mu \mathrm{l}$ of prepared Epil00 bacteria (see Subheading 3.1.4) into a $1.5 \mathrm{ml}$ tube each, incubate both mixtures for $20 \mathrm{~min}$ at $37^{\circ} \mathrm{C}$ by the use of a thermomixer, then plate the total volumes of $110 \mu \mathrm{l}$ of transfected Epil00 cells each on an LB plate with CA (petri dish), and incubate at $37^{\circ} \mathrm{C}$ overnight. To make sure that the packaging efficiency is sufficient to establish a complex fosmid library, count the numbers of colonies grown from each of the phage dilutions to calculate the total expected number of circular fosmid clones packaged by phages ( see step 2) as follows: (Number of colonies $\mathrm{x}$ dilution factor $\times 1000 \mu \mathrm{l}$ ) divided by 


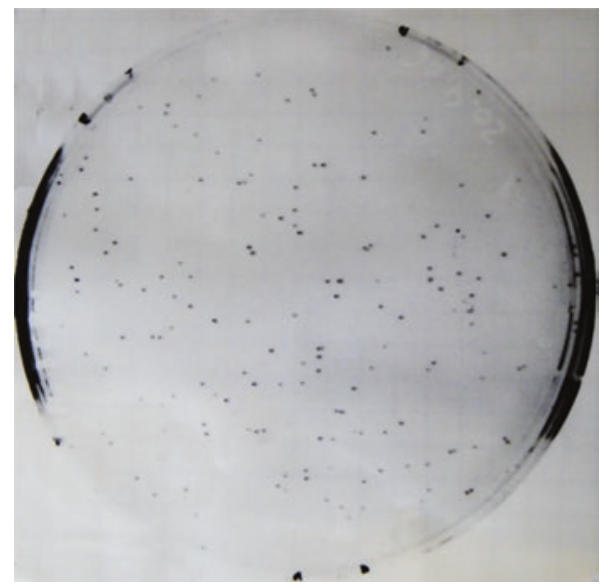

Fig. 3 Titer testing to determine the total number of fosmid clones expected from mass transfection. A petri dish (agar plate with chloramphenicol) with multiple bacterial colonies is shown; these were grown overnight from Epi100 bacteria transfected with a 1:102 phage dilution. 166 colonies are counted, allowing calculation of the total number of expected fosmid clones to nearly $1.7 \times 10^{6}$, sufficient to generate an individual fosmid library from a single cloning procedure

(volume of plated phage particles in $\mu \mathrm{l}$ ) ( see Note $\mathbf{1 5}$ and Fig. 3). If the expected total number of fosmid clones is below $1.44 \times 10^{6}$ - that is, if less than 150 fosmid clones are counted from plating the $1: 10^{2}$ phage dilution-start a second fosmid cloning round beginning with the first step, shearing of $8 \mu \mathrm{g}$ HMW gDNA. Store the packaged phages in PDB at $4{ }^{\circ} \mathrm{C}$ until the required number of fosmid clones has been obtained.

3.1.6 Mass Transfection of E. Coli
Make sure that all the following steps are performed in one workflow under sterile conditions. Specifically, work under a sterile laminar flow hood and use sterile media only.

1. To begin with, prepare $440 \mathrm{ml} \mathrm{LB}$ broth with $10 \mathrm{mM} \mathrm{MgSO}_{4}$ and $12.5 \mu \mathrm{g} / \mathrm{ml} \mathrm{CA}$, aliquot the prepared LB into $3 \times 96$-deep well plates, $1.5 \mathrm{ml}$ per well.

2. For mass transfection, prepare all phage packaging reactions required to generate $1.5 \times 10^{6}$ fosmid clones and determine their total volume (see Subheading 3.1.5, step 3). Fill an Erlenmeyer flask with the prepared Epil00 bacteria (see Subheading 3.1.4) to bring the final transfection volume up to $30 \mathrm{ml}$. For example, if one phage packaging reaction of $1 \mathrm{ml}$ has proven sufficient to achieve a total of $1.5 \times 10^{6}$ phages, start with $29 \mathrm{ml}$ of Epil00 cells.

3. Add the phages to the Epil00 cells and let the phage particles adsorb for $20 \mathrm{~min}$ at $37^{\circ} \mathrm{C}$. Preserve an aliquot of $20 \mu \mathrm{l}$ from the mass transfection mix, expected to contain $\sim 1000$ fosmid clones, in order to control the clone pool complexity; store on ice until use in Subheading 3.1.7, step 2. 
3.1.7 Partitioning Fosmid Clones into Pools and Amplification of Fosmid Library
Partitioning the fosmid clones into $3 \times 96$-deep well plates, i.e., 288 wells, allows generation of "haploid clone pools" that contain 5000 fosmid clones per well. This library format minimizes the probability that complementary parental haplotypes co-occur in one well. Thus, multiple fosmid pools, each representing a random mixture of $\sim 40 \mathrm{~kb}$ haploid DNA segments covering $5 \%$ of the haploid genome, can be sequenced to saturate both haploid genomes. The partitioning and amplification of an entire fosmid library with agar plates is very labor-, and cost-intensive. To simplify the procedure we have chosen to use liquid cultures at this stage as described below (see Note 16).

1. Dispense $100 \mu \mathrm{l}$ of the mass transfection into each well of the $3 \times 96$-deep well plates, expected to correspond to 5000 fosmid clones per well, and cover with breathable seal. Each well contains prepared LB broth (see Subheading 3.1.6, step 1).

2. After partitioning fosmid clones into deep wells, incubate for $20 \mathrm{~h}$ at $37^{\circ} \mathrm{C}$ at $200 \mathrm{rpm}$ in a shaking incubator to amplify the clones.

3. Take the $20 \mu \mathrm{l}$ sample preserved in Subheading 3.1.6, step 3, and plate $5 \mu \mathrm{l}$ (expected to correspond to $\sim 250$ colonies) and $2.5 \mu \mathrm{l}$ (expected to correspond to $\sim 125$ colonies) each on a $10 \mathrm{~cm} \mathrm{LB}$ plate with CA and incubate at $37^{\circ} \mathrm{C}$ overnight.

4. The next day, count the number of grown clones. Determine the obtained clone pool complexity as follows: (Number of $\mathrm{cfu} /$ Volume of plated fosmid clones $)=($ Number of $\mathrm{cfu}$ per well/Dispensed mass transfection volume). For example, if $260 \mathrm{cfu}$ are counted on an LB plate, the number of cfu, or fosmid clones that have been obtained per well in the library is calculated as $(260 \mathrm{cfu} / 5 \mu \mathrm{l})=($ Number of cfu per well $/ 100 \mu \mathrm{l})$, and is 5200 in this case

5. For long-term storage of fosmid libraries, aliquot $250 \mu \mathrm{l}$ of glycerol $(90 \%)$ into each of the wells of the $3 \times 96$-well plates to a final volume of $1.85 \mathrm{ml}$, $\mathrm{mix}$ and store at $-80{ }^{\circ} \mathrm{C}$.

6. In order to prepare working plates, thaw glycerol stock deep well plates and pipet $150 \mu \mathrm{l}$ per well from the deep well stock plate into a 96-well working plate; make sure to pipet deep well content up and down at least once before removing $150 \mu \mathrm{l}$ to capture all individual clones. Use a plate with wells of at least $250 \mu \mathrm{l}$ of capacity.

7. To prepare super-pool plates with 15,000 fosmid clones per well, combine the three 96-well working plates into a single 96-well plate. Transfer $50 \mu \mathrm{l}$ from each 96-well working plate into a single, new 96-well plate; use an 8-channel pipette to always combine the wells with identical positions on the working plates. Cover the super-pool plate with breathable seal, pack into aluminum foil and store in $-80{ }^{\circ} \mathrm{C}$ freezer. 


\subsection{Isolation of Fosmid DNA from Fosmid Clone Pools}

\subsubsection{Plating and Scraping Fosmid Super-Pools}

\subsubsection{Extraction} of Fosmid Super-Pool DNA
Due to the usage of the EpiFos single-copy vector, each transfected Epil00 bacterium will only contain one fosmid clone. To isolate sufficient amounts of fosmid DNA from single fosmid super-pools for sequencing library preparation, while preserving library complexity, the use of LB agar plates for this amplification step (see Note 16) has proven to be indispensable. As a consequence of such large-scale cultivation of Epi 100 cells, large amounts of Epil00 genomic DNA and proteins must be removed, requiring additional purification steps. The fosmid clones scraped from the agar plate are divided into two portions for more efficient exonuclease digest of bacterial genomic DNA, and the proteins are filtrated before extraction of fosmid insert DNA (see Note 17).

As outlined in the Introduction, routinely, 40-48 super-pools per fosmid library are sequenced to be able to phase approximately $85-92 \%$ of the heterozygous SNPs. Thus, this number of superpools was amplified for subsequent DNA isolation, preparing two plates per super-pool.

1. Prepare two large $(22 \times 22 \mathrm{~cm})$ LB agar plates per super-pool with CA. Thaw 96-well super-pool plates with 15,000 fosmid clones per well on ice. Scratch thawed fosmid-glycerol mixture with the inoculating loop to yield approximately $3 \mu \mathrm{l}$ fosmidglycerol mixture per well, and mix with $1 \mathrm{ml} \mathrm{LB}$ medium and CA in a $1.5 \mathrm{ml}$ tube. Pipet $500 \mu \mathrm{l}$ of the LB-clone mix onto one LB plate and the other half of the LB-clone mix onto the second LB plate, spread with Drigalski spatula, and incubate at $37^{\circ} \mathrm{C}$ overnight.

2. To scrape the clones, rinse $3 \times 5 \mathrm{ml} \mathrm{LB}$ medium over the first incubated LB plate, carefully scrape colonies from agar plate with a Drigalski spatula, and pipet clones from LB plate into a single $50 \mathrm{ml} \mathrm{Falcon}$ tube. Repeat for the second LB plate containing the second half of the super-pool, and pipet collected clones into a new $50 \mathrm{ml}$ Falcon tube.

1. Chill centrifuge to $4{ }^{\circ} \mathrm{C}$, and centrifuge the two $50 \mathrm{ml}$ Falcon tubes each containing half of the clones from a single superpool at $6000 \times g$ for $15 \mathrm{~min}$. For extraction, the QIAGEN Large-Construct Kit is used, which contains most of components, reagents, and buffers. Resuspend pellet in $10 \mathrm{ml} \mathrm{Pl}$ Buffer. Add $10 \mathrm{ml} \mathrm{P2}$ Buffer and mix by inverting rigorously $(5 \times)$ to lyse cells (but do not vortex), leave reaction for $2 \mathrm{~min}$ at room temperature, stop cell lysis reaction by adding $10 \mathrm{ml}$ prechilled $\left(4^{\circ} \mathrm{C}\right) \mathrm{P} 3$ buffer, and cool reaction $10 \mathrm{~min}$ on ice. Centrifuge the Falcon tubes for $30 \mathrm{~min}$ at $4{ }^{\circ} \mathrm{C}$ at a minimum of $12,500 \times g($ see Note 18$)$.

2. Prepare two fluted filters, wet the filter paper with $\mathrm{dH}_{2} \mathrm{O}$ and put each filter onto a new $50 \mathrm{ml}$ Falcon tube, pipet the supernatant (containing fosmid DNA) from the first centrifuged 
Falcon tube onto one pre-wetted fluted filter, and the supernatant from the second Falcon tube onto a second pre-wetted fluted filter, wait until supernatant has been filtrated.

3. Equilibrate two QIAGEN-tips 500 (from the QIAGEN Large-Construct Kit) with $10 \mathrm{ml}$ QBT Buffer, transfer the clear filtrate from each Falcon tube to one QIAGEN-tip, wash the tip twice with $30 \mathrm{ml}$ QC Buffer, elute fosmid super-pool DNA with $15 \mathrm{ml}$ preheated $\left(65^{\circ} \mathrm{C}\right)$ QF Buffer. Pool the eluates from both Falcon tubes, which are from a single fosmid super-pool.

4. Precipitate fosmid super-pool DNA by adding 0.7 volumes $(21 \mathrm{ml}$ ) isopropanol, $\mathrm{mix}$ and centrifuge for $40 \mathrm{~min}$ at $12,500 \times g$. Wash pellet with $5 \mathrm{ml}$ ethanol $(70 \%)$, centrifuge for $30 \mathrm{~min}$ at $12,500 \times \mathfrak{g}$, air-dry pellet at room temperature, and redissolve DNA in $9.5 \mathrm{ml}$ EX Buffer.

5. To remove contaminating genomic DNA from the EPII00 bacteria and nicked or damaged large-construct DNA, an exonuclease digestion is strongly recommended. Therefore, prepare first $100 \mathrm{mM}$ ATP solution: Dissolve $2.75 \mathrm{~g}$ ATP (adenosine 5'triphosphate disodium salt, anhydrous, MW $551.14)$ in $40 \mathrm{ml}$ distilled water, adjust the $\mathrm{pH}$ to 7.5 with $10 \mathrm{M} \mathrm{NaOH}$, bring the volume up to $50 \mathrm{ml}$, distribute into $300 \mu \mathrm{l}$ aliquots, and store at $-20^{\circ} \mathrm{C}$. Secondly, prepare ATPdependent Exonuclease by resuspending $80 \mu \mathrm{g}$ ATPDependent Exonuclease in $225 \mu$ l Exonuclease Solvent. Then add $200 \mu \mathrm{l}$ ATP-dependent Exonuclease and $300 \mu \mathrm{l}$ of the $100 \mathrm{mM}$ ATP solution to dissolved DNA to remove noncircular DNA from the bacterial genome, mix thoroughly, and incubate reaction mix at $37^{\circ} \mathrm{C}$ overnight.

6. Equilibrate one QIAGEN-tip 500 with $10 \mathrm{ml}$ QBT buffer, mix the exonuclease-digested fosmid super-pool DNA with $10 \mathrm{ml}$ QS buffer, and transfer the whole DNA mix to QIAGEN-tip 500. After the DNA has passed the tip, wash two times with $30 \mathrm{ml}$ QC Buffer, elute and precipitate fosmid super-pool DNA as described in steps 3 and 4, resuspend airdried DNA pellet in $300 \mu \mathrm{l}$ TE, and dissolve at room temperature overnight. Transfer fosmid DNA into a new $1.5 \mathrm{ml}$ Eppendorf tube and rinse Falcon tube with additional $100 \mu \mathrm{l}$ TE to collect all fosmid super-pool DNA. Check the quality and quantity of extracted fosmid super-pool DNA on a $1.5 \%$ agarose gel, run at $120 \mathrm{~V}$ for $20 \mathrm{~min}$ (see Fig. 4).

3.3 Fosmid PoolBased Next Generation Sequencing Library Preparation
At the time of developing and applying our method to production, we used a SOLiD System from ABI/Life Technologies. The extracted super-pool fosmid DNA can also be analyzed in conjunction with any other NGS technology following the manufacturer's protocols for NGS sequencing library preparation. All reagents have been provided with the SOLiD system sequencing kits, if not 


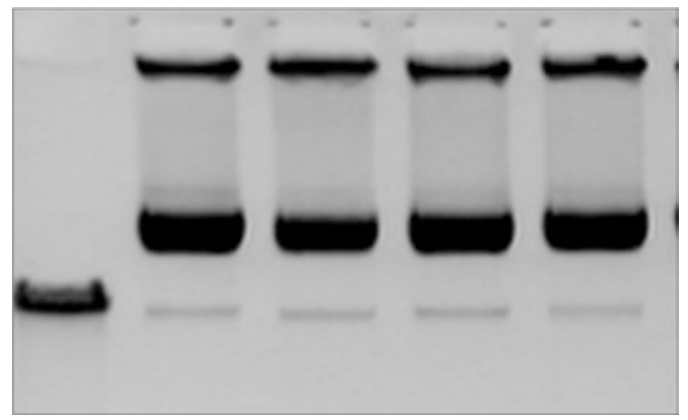

Fig. 4 Fosmid super-pool DNA controlled after extraction. The DNA isolated from four super-pools is shown resolved on a $1.5 \%$ agarose gel stained with ethidium bromide; on the left, (linearized) fosmid control (FC) DNA, the faint DNA bands of the same size as FC DNA seemingly represent linear fosmid DNA, which has escaped purification. The larger, thick bands represent the circular fosmid DNA

3.3.1 Barcoded

Preparation of Fragment Libraries specified otherwise. The fosmid DNA isolated from a single fosmid super-pool is used as input to prepare a sequencing library; thus, up to 96 sequencing libraries could be generated if one would want to utilize all super-pools from an individual fosmid pool library. To allow parallel processing of multiple NGS sequencing libraries, we created barcode tags by modification of the Pl-adaptor sequence. With the barcoded sequences, up to 16 super-pools could be multiplexed later in the clonal amplification step and the sequencing run.

In this case, the isolated fosmid super-pool DNA is used as input to create a library of short DNA sequencing template molecules $100-150$ bp in length.

1. At least $30 \mathrm{~min}$ ahead of time, prepare Covaris S2 Sonicator for DNA shearing. Fill with deionized water to mark level 12 (water should cover glass microtube), degas for $30 \mathrm{~min}$ while continuously keeping the pump on, then cool down to $4{ }^{\circ} \mathrm{C}$. Make sure that no bubbles appear at the bottom of the tube after degasing has finished (see Note 19).

2. Use $3 \mu \mathrm{g}$ of extracted fosmid pool DNA in $100 \mu \mathrm{l}$ Low TE buffer, place capped Covaris microtube into Covaris G7 adaptor. Transfer $100 \mu \mathrm{l}$ DNA into microtube using extra thin pipet tip to avoid damaging of microtube presplit septa (cap of Covaris microtube) and make sure to not introduce an air bubble at the bottom of the microtube; shear the input DNA for $360 \mathrm{~s}$ ("DC" $20 \%$, intensity 5 , cycles burst 200 , time $60 \mathrm{~s}$, six cycles, frequency sweeping mode) to generate fragments between 100 and 150 bp in size.

3. Control the shearing result by running a Lonza FlashGel System with a $2.2 \%$ Lonza FlashGel Cassette: mix $3 \mu$ l of sonicated DNA with $3 \mu \mathrm{l} 1 \times$ Loading Dye (diluted from $6 \times$ Orange DNA Loading Dye), pipet $2.5 \mu$ Low Range DNA Ladder in 
the first and last lane, run gel at $275 \mathrm{~V}$ for $6 \mathrm{~min}$, visualize DNA while migrating. If the bulk of sheared DNA is above a size range of 100-150 bp, repeat Covaris shearing as described above for $180 \mathrm{~s}$, and control fragment sizes again on a Lonza gel. Concentrate sheared DNA with QIAGEN MinElute columns (from MinElute Gel Extraction Kit, QIAGEN) as per manufacturer's protocol, elute twice in $21 \mu$ l elution buffer, take $1.5 \mu \mathrm{l}$ of eluted sample to measure final DNA concentration, and transfer sheared DNA to a $1.5 \mathrm{ml}$ LoBind tube.

4. End-repair of fragments for blunt-end ligation: mix $40 \mu \mathrm{l}$ of sheared fosmid pool DNA, $6 \mu$ l End-Repair Buffer, $6 \mu \mathrm{l} \mathrm{10 \times}$ dNTPs, $6 \mu \mathrm{l}$ ATP, $2 \mu$ End-Repair enzyme from the End-It DNA End-Repair Kit (Epicentre), incubate at $21^{\circ} \mathrm{C}$ in a thermoshaker for $30 \mathrm{~min}$, purify with MinElute Columns as per protocol, elute twice in $20 \mu$ l elution buffer, quantify with Qubit per manufacturer's protocol.

5. Size selection of end-repaired fragments: run a $4 \%$ Reliant NuSieve 3:1 agarose gel with ethidium bromide (see Note 20), mix total volume of end-repaired DNA with $7 \mu$ l Loading Dye $(6 \times)$, load three slots each with $15 \mu$ DNA, keep one well on both sides of the samples empty, use $5 \mu$ l Low Range DNA ladder at both sides of the gel, run for 40 min at $110 \mathrm{~V}$ $(210 \mathrm{~mA})$. Visualize sample on an UV Multibright Transilluminator shortly, use UV protection shield to excise the DNA between bands 100 and 150 bp (see Fig. 5a), transfer gel piece into one $2 \mathrm{ml}$ tube and cut into smaller pieces, weigh
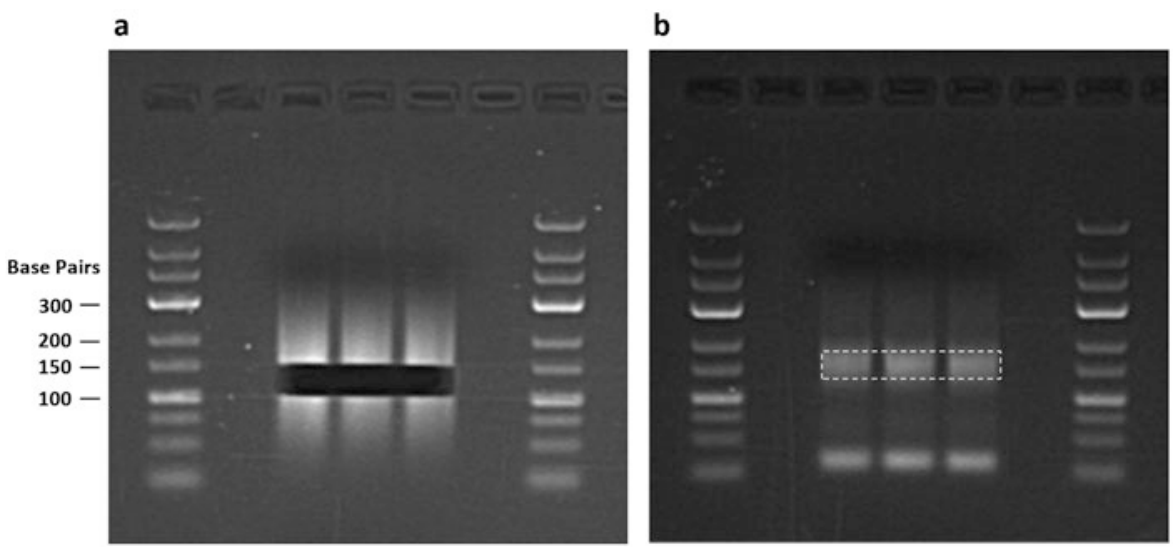

Fig. 5 Size-selection of sheared fosmid super-pool DNA for preparation of fragment sequencing libraries. (a) Three aliquots of sheared, end-repaired fosmid clone DNA fragments before ligation of adaptor sequences are shown resolved on a $4 \%$ Reliant NuSieve 3:1 agarose gel (Lonza) with ethidium bromide together with a Low Range DNA Ladder, and a gel piece containing DNA fragments of 100-150 bp in size has been cut out. (b) The excised DNA fragments are shown resolved after ligation of adaptor sequences, and are now slightly larger, in the range of 150-200 bp in size. These ligation products are again excised, as indicated by the white dashed lines, for subsequent purification and nick translation. The bands at the bottom represent excess adaptor sequences that were not ligated 
tared tube and digest gel as described by the manufacturer's protocol, see also Subheading 3.1.3, step 4; then purify with QIAGEN MinElute columns, elute twice in $25 \mu$ l elution buffer, and use $1 \mu \mathrm{l}$ to determine DNA concentration with Qubit (see Note 21).

6. The barcoding of a fosmid super-pool DNA sample is achieved by ligating a modified $\mathrm{Pl}$ adaptor sequence containing a unique barcode sequence tag of 6 bp (see Note 22 including a list of these unique barcode sequences) to the DNA fragments instead of the universal adaptors provided by the SOLiD Fragment Library Oligo Kit. First, the necessary picomoles (pmol) of adaptor required for ligation are determined according to the following formula:

$1 \mu \mathrm{g} \mathrm{DNA} \times 10^{6} \mathrm{pg} / \mu \mathrm{g} \times 1 \mathrm{pmol} / 660 \mathrm{pg} \times \mathrm{l} /($ Average insert fragment size $)=17 \mathrm{pmol}$

$(\# \mu \mathrm{g} D \mathrm{DN}) \times(17$ pmol DNA $)=(\#$ pmol DNA for adaptor ligation)

(\# pmol DNA for adaptor ligation $) \times(30)=(\#$ pmol adaptors needed)

(\# pmol adaptors needed $) /(\#$ pmol $/ \mu$ l stock $)=(\# \mu$ l adaptor needed)

With an average size of 125 bp for sheared DNA fragments, the volume of universal adaptors can be calculated as follows: (Total amount of purified DNA in pg/660)/125×(30/50).

7. Ligation reaction: pipet $47-49 \mu$ of purified fosmid pool DNA into a $1.5 \mathrm{ml}$ LoBind tube, add $100 \mu \mathrm{l} 2 \times$ Quick Ligation Buffer (from the Quick Ligation Kit, NEB), P1 and P2 adaptors $(50 \mathrm{pmol} / \mu \mathrm{l})$ as calculated in step 6 , and $5 \mu \mathrm{l}$ Quick Ligase, fill with $\mathrm{dH}_{2} \mathrm{O}$ to a total reaction volume of $200 \mu \mathrm{l}$, incubate exactly $10 \mathrm{~min}$ in a thermomixer preheated to $21^{\circ} \mathrm{C}$, and stop the reaction instantly by adding $600 \mu \mathrm{l}$ ERC buffer. Purify the reaction with MinElute columns, using the QIAGEN MinElute Reaction Cleanup Kit according to the manufacturer's protocol, and elute twice in $20 \mu \mathrm{l}$ elution buffer to a final sample volume of $40 \mu \mathrm{l}$.

8. Size-selection of ligation products: mix the total sample volume with $7 \mu \mathrm{l} 6 \times$ Loading Dye, load sample in three aliquots of $16 \mu \mathrm{l}$ into three wells of a Reliant $4 \%$ NuSieve 3:1 agarose gel (with ethidium bromide), keep one well on each side empty, use Low Range DNA Ladder on both sides of gel, run for $40 \mathrm{~min}$ at $110 \mathrm{~V}$, visualize on UV Transilluminator, sizeselect as described earlier (Subheading 3.3.1, step 5) the band between $150 \mathrm{bp}$ and $200 \mathrm{bp}$ (size corresponds to fosmid pool DNA plus ligated adaptor sequences; see Fig. 5b), and weigh gel slices in tared $2.0 \mathrm{ml}$ tube. If gel slice weighs more than $400 \mathrm{mg}$, divide gel pieces into two tubes (see Note 23 ). 
9. Purification of size-selected ligation products with MinElute Gel Extraction Kit (QIAGEN) according to the manufacturer's protocol: add 6 volumes QG buffer to 1 volume (equivalent to $100 \mathrm{mg}$ or $100 \mu \mathrm{l}$ ) of gel, dissolve the gel by vortexing the tube at room temperature, vortex tube every 2-3 min for minimally 15 min until gel has completely dissolved. Add 1 gel volume of isopropanol, invert the sample, apply to MinElute column and centrifuge for $1 \mathrm{~min}$, discard flow-through, add $500 \mu \mathrm{l}$ QG buffer and centrifuge $1 \mathrm{~min}$, discard flow-through, wash with $750 \mu \mathrm{l}$ PE buffer, centrifuge $1 \mathrm{~min}$, discard flowthrough and centrifuge again $1 \mathrm{~min}$, place the MinElute column in a new $1.5 \mathrm{ml}$ LoBind tube, elute DNA with $18 \mu \mathrm{l}$ of elution buffer twice, and use $1 \mu$ for DNA concentration measurement with Qubit (see Note 24).

10. Nick translation: transfer $34 \mu \mathrm{l}$ of adaptor-ligated DNA into a new $1.5 \mathrm{ml}$ tube, add $4 \mu \mathrm{l} 10 \times$ NEBuffer 2 (NEB), $0.8 \mu \mathrm{l}$ dNTP-Mix $(100 \mathrm{mM})$ and $1 \mu \mathrm{l}$ DNA Polymerase I $(10 \mathrm{U} / \mu \mathrm{l})$ (NEB), fill with water to $40 \mu \mathrm{l}$, mix and incubate reaction for $30 \mathrm{~min}$ at $16^{\circ} \mathrm{C}$ in a thermomixer; if necessary, inactivate the enzyme at $65{ }^{\circ} \mathrm{C}$ for $10 \mathrm{~min}$ and store reaction at $4{ }^{\circ} \mathrm{C}$ until large-scale PCR setup (see Subheading 3.3.3).

3.3.2 Barcoded Preparation of Mate-Paired Libraries
Mate pairs are defined as a pair of DNA fragments that originate from the two ends of the same genomic DNA fragment, the distance between the two mates depends upon the size of the original genomic DNA fragment (insert size), and can range from $~ 100$ bp to several $\mathrm{kb}$. To create mate-paired tags, a linear DNA fragment needs to be circularized by the use of LMP CAP adaptors connected to an internal biotinylated adaptor. These adaptors are provided by the SOLiD Mate-Paired Library Oligo Kit from Applied Biosystems (see also Subheading 2.3.2). The resulting DNA circle has one nick in each strand due to the LMP CAP adaptor. During nick translation, the length of the fragments that will be released after T7 exonuclease and SI nuclease digest depends on the time and temperature of the DNA polymerase reaction. The largest part of the inserted, circularized DNA is cut out enzymatically, which leaves the two ends of the inserted DNA as mate-paired tags. After ligation of universal adaptors and subsequent PCR amplification, the mated tags $(2 \times 50 \mathrm{bp})$ can be sequenced together, allowing computational detection of larger structural genome variants. Each mate-paired library can also be indexed by using modified P2-adaptors containing a unique barcode sequence.

1. Shear $5 \mu \mathrm{g}$ of extracted fosmid pool DNA in $125 \mu$ l nucleasefree water with the HydroShear (standard assembly) to generate gDNA fragment sizes of $1-2 \mathrm{~kb}$ (speed code 5, 20 cycles), 3-4 kb (speed code 13, 20 cycles), and 5-10 kb (speed code 15,5 cycles). Control the shearing results on a $0.8 \%$ agarose gel ( see Note 25). 
2. Purify sheared fosmid pool DNA with QIAquick Gel Extraction Kit: add 3 volumes QG buffer and I volume isopropanol to sheared DNA, transfer $750 \mu \mathrm{l}$ of DNA-QG buffer mix to QIAquick column (maximum DNA binding capacity $10 \mu \mathrm{g}$ per column), wait for $2 \mathrm{~min}$ at room temperature, centrifuge 1 min at minimally $13,000 \times g$ and discard flow-through, repeat the steps until the entire sample has been loaded, wash column with $750 \mu \mathrm{l} \mathrm{PE}$ buffer, centrifuge for $2 \mathrm{~min}$ at minimally $10,000 \times \mathfrak{g}$, repeat centrifugation, air-dry column for $2 \mathrm{~min}$, transfer column to a new $1.5 \mathrm{ml}$ LoBind tube, elute by adding $30 \mu \mathrm{lEB}$ buffer to column, let stand for $2 \mathrm{~min}$, centrifuge column at minimally $10,000 \times g$ for $1 \mathrm{~min}$, repeat elution and centrifugation step.

3. End-repair with End-It DNA End-Repair Kit (Epicentre) as per manufacturer's protocol; the total reaction volume is 10-fold the amount of input DNA (in $\mu \mathrm{g}$ ). Purify with QIAquick columns ( see step 2).

4. Ligation of end-repaired sheared fosmid pool DNA to LMP Cap Adaptors resulting in a nick on each DNA strand during circularization: first calculate the molarity of each DNA fragment size (insert) based on the formula $\left(\left(10^{6} / 660\right) \times(1 /\right.$ average insert size $)=\mathrm{X} \mathrm{pmol} / \mu \mathrm{g}$ DNA. Use the molarity to calculate the amount of adaptor needed for the ligation reaction in $\mu \mathrm{l}(($ total amount of input DNA $\times$ pmol of DNA fragment $\times 100) /(50 \mathrm{pmol})=\mu \mathrm{l}$ adaptor $)$. Combine $150 \mu \mathrm{l} 2 \times$ Quick Ligase Reaction Buffer (NEB), the calculated volume of LMP cap adaptor, 7.5 $\mu$ l Quick Ligase enzyme (NEB), the total amount of input DNA and add $\mathrm{dH}_{2} \mathrm{O}$ to have a $300 \mu \mathrm{l}$ reaction mix, then incubate the mix at room temperature for 10 min. Purify with QIAquick columns (see step 2).

5. Size selection: To remove unbound CAP adaptors, prepare a $0.8 \%$ TAE agarose gel (Applied Biosystems) with ethidium bromide, mix ligated DNA with 10x loading dye, load $11 \mu \mathrm{l}$ of sample per well, keep one well empty on each side of the DNA sample, load $1 \mu$ of the $1 \mathrm{~kb}$ size DNA Ladder at both sides of the gel, run the gel at $120 \mathrm{~V} / \mathrm{cm}$, visualize the gel on an UV illuminator, excise a gel slice corresponding narrowly to the insert size and extract DNA with QIAquick Gel Extraction Kit as per protocol.

6. Circularize LMP CAP adaptor-ligated DNA with a biotinylated internal adaptor: for circularization, the components are calculated per $\mu \mathrm{g}$ of size-selected insert DNA: for a $1-2 \mathrm{~kb}$ insert size use $182.5 \mu \mathrm{l}$ of $2 \times$ Quick Ligase Buffer, $1.5 \mu \mathrm{l}$ Internal Adaptor $(2 \mu \mathrm{M}), 9 \mu \mathrm{l}$ Quick Ligase, and add $\mathrm{dH}_{2} \mathrm{O}$ to a volume of $365 \mu \mathrm{l}$. Accordingly, circularization of 3-4 kb insert sizes (or $5-10 \mathrm{~kb}$ insert sizes, respectively) require $280 \mu \mathrm{l}(360 \mu \mathrm{l})$ of $2 \times$ Quick Ligase Buffer, $0.65 \mu \mathrm{l}(0.4 \mu \mathrm{l})$ 
Internal Adaptor, $14 \mu \mathrm{l}(18 \mu \mathrm{l})$ Quick Ligase, then add $\mathrm{dH}_{2} \mathrm{O}$ to a total volume of $560 \mu \mathrm{l}(720 \mu \mathrm{l})$. Incubate the reaction for $10 \mathrm{~min}$ at room temperature, purify with QIAquick Gel Extraction Kit (see Subheading 3.3.2, step 2). The internal adaptor is biotin-labeled, enabling the specific binding of circularized DNA to streptavidin beads later in the protocol (see step 11) (see Note 26).

7. Isolate circularized DNA by digesting un-circularized DNA with Plasmid Safe ATP DNAse: combine $5 \mu \mathrm{l} 25 \mathrm{mM}$ ATP, $10 \mu 110 \times$ Plasmid-Safe Buffer, the total volume of circularized DNA from step 6, add $0.33 \mu$ l Plasmid-Safe DNAse (10 U/ $\mu \mathrm{l})$ per $\mu \mathrm{g}$ of circularized DNA, then add $\mathrm{dH}_{2} \mathrm{O}$ to a total reaction volume of $100 \mu \mathrm{l}$ and incubate in a thermomixer at $37^{\circ} \mathrm{C}$ for $40 \mathrm{~min}$. The DNAse will digest only noncircularized DNA fragments. Purify with QIAquick Gel Extraction Kit Protocol (see Subheading 3.3.2, step 2) and quantify circularized DNA with Qubit; a minimum of $200 \mathrm{ng}$ circularized DNA should be recovered to proceed with the next steps. For more complex genomes, $600 \mathrm{ng}-1 \mu \mathrm{g}$ circularized DNA is recommended for a high-complexity library.

8. The size of the mate-paired tags to be produced in this step critically depends on the reaction temperature and time of the nick-translation of circularized DNA: work on ice, per $1000 \mathrm{ng}$ of circularized DNA add $5 \mu \mathrm{l}$ of $100 \mathrm{mM}$ dNTP mix, $50 \mu \mathrm{l}$ $10 \times$ NEBuffer 2, circularized DNA, and bring up to a total volume of $490 \mu \mathrm{l}$ with $\mathrm{dH}_{2} \mathrm{O}$; chill the reaction for at least 5 min by putting the tube into an ice-water bath, then quickly add $10 \mu \mathrm{l}$ DNA polymerase $\mathrm{I}(10 \mathrm{U} / \mu \mathrm{l})$; mix, incubate the reaction at $0{ }^{\circ} \mathrm{C}$ for $12-14 \mathrm{~min}$, immediately stop the reaction by adding 3 volumes of Buffer QG and 1 volume of isopropanol and purify with QIAquick Gel Extraction protocol (see Subheading 3.3.2, step 2). The size of mate-paired tags created by DNA polymerase I can be controlled by reaction time and temperature (see Note 27).

9. T7 exonuclease digest to release the mated tags: per $1000 \mathrm{ng}$ of circularized DNA combine $50 \mu \mathrm{l} 10 \times$ NE Buffer 4 and circularized DNA, bring up to a total volume of $480 \mu \mathrm{l}$ with $\mathrm{dH}_{2} \mathrm{O}$, add $20 \mu \mathrm{l}$ T7 exonuclease $(10 \mathrm{U} / \mu \mathrm{l})$ and mix and incubate the reaction at $37{ }^{\circ} \mathrm{C}$ for $30 \mathrm{~min}$. Purify with QIAquick Gel Extraction Kit according to the manufacturer's protocol (see Subheading 3.3.2, step 2). T7 exonuclease recognizes the nicks within the circularized DNA created in step 8, and digests the un-ligated DNA strand away from the tags creating a gap in the sequence. This allows cleavage of the mate-paired tags from the circularized template by SI Nuclease (

10. SI Nuclease digest: Use SI dilution buffer to prepare S1 Nuclease with an activity of $1 \mathrm{U} / \mu \mathrm{l}$ (Invitrogen); per $1000 \mathrm{ng}$ 
circularized DNA mix $50 \mu \mathrm{l} 10 \times$ S1 Nuclease buffer, $25 \mu \mathrm{l} 3 \mathrm{M}$ sodium chloride, $50 \mu \mathrm{l} 100 \mathrm{mM}$ magnesium chloride, $20 \mu \mathrm{l}$ of diluted S1 Nuclease, add $\mathrm{dH}_{2} \mathrm{O}$ to a total volume of $500 \mu \mathrm{l}$, incubate the reaction at $37^{\circ} \mathrm{C}$ for $30 \mathrm{~min}$, immediately stop the reaction by adding 3 volumes of QG Buffer and 1 volume of isopropanol, and proceed with the QIAquick Gel Extraction Kit Protocol (see Subheading 3.3.2, step 2). S1 Nuclease removes the non-ligated part of the inserted DNA, leaving a linearized molecule with the ends (tags) of the inserted DNA attached to both sides of the molecule (mate-paired tags).

11. Binding of biotinylated library molecules to Streptavidin beads for purification: preparing Streptavidin Dynabeads for use after the end-repair step. Prepare the Streptavidin binding buffer by mixing $10 \mu \mathrm{l}$ Tris- $\mathrm{HCl}(500 \mathrm{mM}$, ph 7.5), $200 \mu \mathrm{l}$ $5 \mathrm{M}$ sodium chloride, $1 \mu \mathrm{l} 500 \mathrm{mM}$ EDTA and add $289 \mu \mathrm{l}$ $\mathrm{dH}_{2} \mathrm{O}$ to a total volume of $500 \mu \mathrm{l}$. Prepare $\mathrm{l} \times$ Bead Wash Buffer (from the Solid Buffer Kit) by mixing $5 \mu \mathrm{l} 100 \times$ BSA

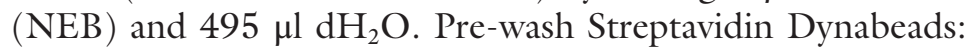
vortex bottle of Streptavidin Dynabeads, transfer $90 \mu \mathrm{l}$ of beads into a $1.5 \mathrm{ml}$ LoBind tube, add $500 \mu \mathrm{l} \mathrm{l} \times$ Bead Wash Buffer. Vortex and spin down, place tube into magnetic stand (Applied Biosystems) and wait until the solution clears. Aspirate the supernatant and discard it, add $500 \mu \mathrm{l} 1 \times \mathrm{BSA}$, and vortex $15 \mathrm{~s}$. Spin down, place tube into magnetic stand until solution clears, aspirate and discard supernatant. Add $500 \mu \mathrm{l}$ of $1 \times$ Bind \& Wash Buffer, vortex $15 \mathrm{~s}$, spin down, place tube into magnetic stand to clear solution, aspirate and discard supernatant. Use pre-washed beads in step $\mathbf{1 3 .}$

12. Combine $10 \mu \mathrm{l}$ End-Repair buffer $(10 \times), 10 \mu \mathrm{l}$ ATP $(10 \mathrm{mM})$, $10 \mu \mathrm{d}$ dNTPs (2.5 mM each), $2 \mu$ l End-Repair Enzyme Mix, a total volume of S1-digested DNA from step 10, then add $\mathrm{dH}_{2} \mathrm{O}$ to a total volume of $100 \mu \mathrm{l}$, incubate the reaction mix for $30 \mathrm{~min}$ at room temperature, stop the reaction by adding $5 \mu \mathrm{l}$ EDTA $(500 \mathrm{mM}), 200 \mu \mathrm{l}$ Streptavidin binding buffer

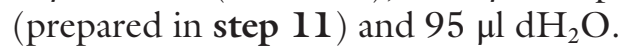

13. Binding the library DNA molecules to Streptavidin beads: add the entire $400 \mu \mathrm{l}$ reaction from step 12 to the pre-washed Streptavidin beads (prepared in step 11), vortex, place the tube into a rotator for $30 \mathrm{~min}$ at room temperature, and spin down the tube.

14. Wash the DNA-Strepatavidin bead complex: place tube with DNA bound to beads into magnetic stand until solution clears. Remove and discard supernatant with pipet, remove tube from magnetic rack, and add $500 \mu \mathrm{l} \times$ Bead Wash Buffer (prepared in step 11). Transfer the suspension to a new $1.5 \mathrm{ml}$ LoBind tube, vortex for $15 \mathrm{~s}$, spin down, and resuspend in $500 \mu \mathrm{l} \mathrm{l} \times$ Bind \& Wash Buffer. Vortex and spin down the solution and 
clear on magnetic rack. Discard the supernatant again, and repeat washing step with another $500 \mu \mathrm{l} \mathrm{l} \times$ Bind \& Wash Buffer. Resuspend the beads in $500 \mu \mathrm{l} 1 \times$ Quick Ligase Buffer, vortex for $15 \mathrm{~s}$, spin down and clear suspension on magnetic rack. Discard supernatant a last time, and resuspend beads in $97.5 \mu \mathrm{l} \times$ Quick Ligase Buffer.

15. Ligate P1 and P2 adaptors to end-repaired mate-paired molecules: calculate the necessary volume of $\mathrm{Pl}$ and $\mathrm{P} 2$ adaptors by using the formula in Subheading 3.3.1, step 6, with the size of circularized DNA corresponding to the average insert size. Combine $97.5 \mu \mathrm{l}$ of the DNA-bead complex, the calculated volume of P1 and P2 Adaptor ( $50 \mathrm{pmol} / \mu \mathrm{l} \mathrm{each})$ and $2.5 \mu \mathrm{l}$ Quick Ligase, and incubate the reaction for $15 \mathrm{~min}$ at room temperature ( see Note 28).

16. Wash the DNA-bead complex as described in step 14 but modified in the last step: add $500 \mu \mathrm{l} \mathrm{l} \times \mathrm{NEBuffer} 2$ (instead of Quick Ligase Buffer) and resuspend beads in $96 \mu \mathrm{l} \mathrm{l} \times$ NEBuffer 2.

17. Nick translation of library: Add $2 \mu 1100 \mathrm{mM}$ dNTP mix and $2 \mu \mathrm{l}$ DNA Polymerase I $(10 \mathrm{U} / \mu \mathrm{l})$ to the $96 \mu \mathrm{l}$ DNA-bead complex in NEBuffer, incubate the reaction for $30 \mathrm{~min}$ at $16{ }^{\circ} \mathrm{C}$, place tube into magnetic stand until solution clears, remove and discard supernatant, resuspend beads in $500 \mu \mathrm{l}$ Buffer EB, place tube into magnetic stand until cleared, remove supernatant, and resuspend beads in $30 \mu \mathrm{l}$ Buffer EB.

3.3.3 Large-Scale PCR of Fragment and MatePaired Libraries
The library is amplified with the Invitrogen PCR SuperMix. The number of PCR cycles should be as small as possible to avoid PCRrelated biases due to differential amplification of library molecules. Fragment Libraries:

1. To prepare a PCR master mix, pipet $400 \mu$ l PCR SuperMix

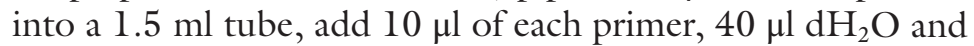
$2.5 \mu \mathrm{l}$ Pfu Polymerase $(2.5 \mathrm{U} / \mu \mathrm{l})$. Before adding the sample, transfer $50 \mu \mathrm{l}$ of master mix without DNA sample into a new $200 \mu \mathrm{l}$ tube (negative PCR control). Add $40 \mu \mathrm{l}$ of nick-translated DNA (see Subheading 3.3.1, step 10) to the remaining master mix, vortex, and transfer four aliquots into new $200 \mu \mathrm{l}$ PCR strips (see Note 29). Run large-scale PCR program $\left(5\right.$ min at $95^{\circ} \mathrm{C}$, hold; few cycles (see Note 30 ) 15 s at $95^{\circ} \mathrm{C}$, 15 s at $62^{\circ} \mathrm{C}, 60$ s at $70{ }^{\circ} \mathrm{C} ; 5$ min at $70{ }^{\circ} \mathrm{C}$, hold; $4{ }^{\circ} \mathrm{C}$, forever, hold); the number of PCR cycles critically depends on the amount of input DNA as measured after purification of nick-translated DNA.

2. Purify PCR reaction with MinElute columns, elute in $60 \mu \mathrm{l}$, add $10 \mu \mathrm{l}$ loading dye $(6 \times)$, load the sample on a $4 \%$ Reliant NuSieve 3:1 agarose gel, run for $40 \mathrm{~min}$ at $110 \mathrm{~V}$, size-select 
PCR product between 150 and $200 \mathrm{bp}$ and control for overamplification; do not proceed, if PCR generates an overamplification band. Gelase digest and extract DNA sample as described (see Subheading 3.3.3, step 4).

Mate-paired libraries:

1. Prepare a PCR master mix for four PCR reactions: mix $200 \mu \mathrm{l}$ PCR SuperMix (Invitrogen), $8 \mu \mathrm{l}$ of Library PCR Primer 1 $(50 \mu \mathrm{M}), 8 \mu \mathrm{l}$ Library PCR Primer $2(50 \mu \mathrm{M}), 1 \mu \mathrm{l}$ cloned Pfu

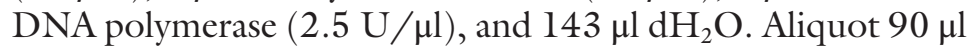
of PCR master mix to a $200 \mu \mathrm{l}$ PCR tube, add $10 \mu \mathrm{d}_{2} \mathrm{O}$ as negative control. To the remaining $270 \mu \mathrm{l}$ PCR master mix, add $27 \mu \mathrm{l}$ DNA-bead complex, vortex, pipet $90 \mu \mathrm{l}$ aliquots into three PCR tubes, run PCR program with initial denaturing step $\left(10 \mathrm{~min}\right.$ at $\left.95^{\circ} \mathrm{C}\right)$ followed by 5 cycles $\left(15 \mathrm{~s}\right.$ at $95^{\circ} \mathrm{C}$, $15 \mathrm{~s}$ at $62^{\circ} \mathrm{C}, 60$ s at $\left.70{ }^{\circ} \mathrm{C}\right) ; 4$ min at $60{ }^{\circ} \mathrm{C}$, hold; $4{ }^{\circ} \mathrm{C}$, forever, hold (see Note 30).

2. Control PCR reaction: Use a $4 \mu \mathrm{l}$ aliquot of PCR reaction and mix with $1 \mu \mathrm{l} 6 \times$ Orange DNA Loading Dye. Load sample on a 2.2\% FlashGel System, load Low Range DNA Ladder in adjacent well, and run the gel for 6 min at $275 \mathrm{~V}$. If fairly robust PCR amplification products are visible on the gel, pool all three PCR reactions into a new $1.5 \mathrm{ml}$ LoBind tube. Otherwise, run two additional cycles on thermal cycler, control an aliquot using a Lonza FlashGel System, repeat thermal cycling steps until amplification is observed.

3. Place $1.5 \mathrm{ml}$ tube on magnetic rack, carefully aspirate supernatant and transfer into a new $2.0 \mathrm{ml}$ LoBind tube. Purify with QIAquick Gel Extraction protocol (see Subheading 3.3.2, step 2).

4. Gel purification step: use a Reliant $4 \%$ NuSieve $3: 1$ agarose gel with ethidium bromide, mix $6 \times$ Orange DNA Loading Dye to mate-paired library to a final $1 \times$ concentration. Load the entire dye-mixed sample DNA in aliquots of $11 \mu \mathrm{l}$ per gel slot. Keeping one well on each side of sample DNA empty, load $2 \mu \mathrm{l}$ Low Range DNA Ladder. Run the gel at $120 \mathrm{~V}$, visualize and excise the sample DNA between bands 275 and $300 \mathrm{bp}$. Weigh gel slices in tared $15 \mathrm{ml}$ conical tubes, add 6 volumes QG buffer per 1 volume gel, and dissolve the gel slices by vortexing at room temperature (do not heat). Add 1 gel volume isopropanol, and mix and invert. Apply $750 \mu \mathrm{l}$ to a QIAquick column, let stand for 2 min at room temperature, centrifuge for $1 \mathrm{~min}$ at minimally $10,000 \times \mathrm{g}$. Repeat until the entire sample has been loaded on column. Wash the column by adding $500 \mu \mathrm{l}$ QG buffer, centrifuge at $10,000 \times g$, wash with $750 \mu \mathrm{l}$ $\mathrm{PE}$ buffer, centrifuge, and air-dry the column for $2 \mathrm{~min}$. Place column on a new $1.5 \mathrm{ml}$ LoBind tube, add $30 \mu \mathrm{l}$ EB buffer, wait $2 \mathrm{~min}$, and centrifuge for $1 \mathrm{~min}$. Quantify the eluted library with the Qubit system as per manufacturer's protocol. 
3.3.4 Preparation of Fragment and Mate-Paired Sequencing Libraries for Emulsion PCR

\subsection{Processing}

Next Generation Sequencing Libraries for Instrument Run
After large-scale PCR purification, library quantification by the use of the Qubit system is sufficiently accurate to calculate the dilution required to obtain picogram concentrations of the library. Alternatively, TaqMan or SybrGreen Real Time PCR can be applied for quantification.

To prepare 500 pM fosmid DNA input samples, measure amplification products by real-time PCR or Qubit fluorometry as per manufacturer's protocol. Prepare several aliquots of $500 \mathrm{pM}$ dilutions of amplified DNA as follows: dilute necessary volume of sample DNA in a volume of $30 \mu \mathrm{l}$ low TE buffer to yield a final concentration of $5 \mathrm{ng} / \mu \mathrm{l}$. Pipet $8 \mu \mathrm{l}$ of the prepared dilution into a new $100 \mu \mathrm{l}$ tube, and add $32 \mu \mathrm{l}$ low TE buffer to prepare a $1 \mathrm{ng} /$ $\mu \mathrm{l}$ dilution. Pipet $4.8 \mu \mathrm{l}$ of $\mathrm{lng} / \mu \mathrm{l}$ dilution into a new tube, and add $75.2 \mu \mathrm{l}$ low TE buffer to a final concentration of $60 \mathrm{pg} / \mu \mathrm{l}$ (500 pM for fragment libraries) (see Note 31).

The SOLiD technology relies on sequencing library amplification on a solid support. To this end, an aqueous and an oil phase are mixed to form an emulsion. During emulsion PCR (ePCR), ideally, multiple copies of one single DNA template molecule are generated on one magnetic bead contained in one emulsion droplet. To avoid multi-clonal amplification, precise DNA quantification and input amounts are essential requirements. Un-templated beads are separated and discarded in a subsequent enrichment step. To ensure that the beads will deposit on the sequencing slide, a 3 'modification of the enriched templated beads is performed. For control, a workflow analysis (WFA) run is carried out with a small portion of the templated beads to analyze the templated bead quality (e.g., multi-clonal beads result in poor sequencing outcome), and the bead concentration.

1. Prepare oil phase (all components provided by the SOLiD ePCR Kit): pipet $35 \mathrm{ml}$ of oil into a $50 \mathrm{ml}$ Falcon tube, add $1.8 \mathrm{ml}$ emulsion stabilizer 1 by using a $2.5 \mathrm{ml}$ glass pipet, and add $400 \mu \mathrm{l}$ of stabilizer 2 with a $1 \mathrm{ml}$ glass pipet. Avoid air bubbles when aspirating stabilizer; in case bubbles have been drawn into pipet, dispense and re-aspirate. Fill Falcon tube with oil to $40 \mathrm{ml}$, close tube and vortex vigorously to emulsify oil components; open cap and let the Falcon tube degas for at least $30 \mathrm{~min}$. Pipet $9 \mathrm{ml}$ of oil phase with a $10 \mathrm{ml}$ syringe into a SOLiD ePCR tube and cap, place tube on IKA Turrax.

2. During degasing of the oil phase, prepare aqueous phase containing the fosmid pool DNA sample. Mix reaction components depending on sequencing library molarity with a total reaction volume of $2720 \mu \mathrm{l}$. For a $1 \mathrm{pM}$ sequencing library

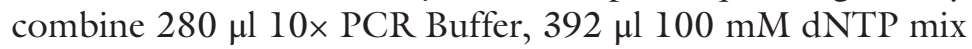
(25 mM per dNTP), $70 \mu \mathrm{l} 1 \mathrm{M} \mathrm{MgCl}, 16.8 \mu \mathrm{l}$ ePCR Primer 2 $(500 \mu \mathrm{M}), 11.2 \mu \mathrm{l}$ ePCR Primer 1 dilution $(10 \mu \mathrm{M}), 5.6 \mu \mathrm{l}$ 
3.4.2 Breaking the Emulsion PCR sequencing library template molecules $(500 \mathrm{pM}), 1,644.4 \mu \mathrm{l}$ nuclease-free water and $300 \mu \mathrm{l}$ AmpliTaq Gold (5 U/1) in a $15 \mathrm{ml}$ Falcon tube, mix by gently inverting the closed tube.

3. Prepare Pl beads: vortex one vial of SOLiD Pl beads, spin down tube, place tube in magnetic rack, wait 1 min until the solution has cleared, discard supernatant, resuspend the beads in $200 \mu \mathrm{l} \mathrm{l} \times$ Bead Block Solution. Vortex, spin down, and place tube in Covaris S2 Sonicator. Run the Bead Block Declump program, place tube in magnetic rack, and wait until solution clears. Discard supernatant, resuspend in $200 \mu \mathrm{l} \mathrm{l} \times$ TEX buffer, vortex, and spin down.

4. Sonicate the prepared Pl beads with the Bead Declump program, immediately add $80 \mu \mathrm{l}$ of sonicated Pl beads to aqueous phase (see step 2). Mix gently by swirling the reaction, and use an Eppendorf semiautomated Xstream pipettor with a $10 \mathrm{ml}$ tip to aspirate $2.8 \mathrm{ml}$ of aqueous phase with bead-DNA complex and Pl beads. Start the IKA Turrax to swirl the oil phase, make sure the program runs at least $5 \mathrm{~min}$. When the IKA Turrax reaches full spinning speed, place Xstream pipettor tip in the middle of ePCR tube and dispense as programmed. Let the oil-aqueous phase mix swirl until IKA Turrax stops (after $5 \mathrm{~min}$ ).

5. Use a $5 \mathrm{ml}$ tip on Eppendorf Repeater Plus Pipette, dispense $100 \mu \mathrm{l}$ emulsion PCR mix per well into a 96-well PCR reaction plate, check bottom of the 96-well plates for air bubbles, spin down if necessary, and run emulsion PCR in a thermal cycler with gold/silver block (program: 5 min at $95^{\circ} \mathrm{C}$, hold; 40 cycles 15 s at $93^{\circ} \mathrm{C}, 30 \mathrm{~s}$ at $62^{\circ} \mathrm{C}, 75$ s at $72{ }^{\circ} \mathrm{C} ; 7$ min at $72{ }^{\circ} \mathrm{C}$, hold; $4{ }^{\circ} \mathrm{C}$, forever, hold).

6. After ePCR finishes, check wells for broken emulsion reactions. Instead of a homogeneous milky suspension, a broken emulsion is indicated by three different layers in a well: a milky suspension, followed by a clear liquid layer (an aqueous phase) and dark freckles from the beads at the bottom of the well. Remove the content of "broken wells" before the next step; do not proceed to the next step if more than four wells show broken emulsion reactions.

1. Under a fume hood, pipet $100 \mu \mathrm{l} 2$-butanol into each well of the 96-well ePCR plate. Pipet up and down to mix, then pipet the broken emulsion PCR suspensions into a $50 \mathrm{ml}$ tray. Transfer into a new $50 \mathrm{ml}$ Falcon tube, and rinse tray with additional 2 -butanol to collect remaining beads from tray. Fill the Falcon tube to $30 \mathrm{ml}$ with 2-butanol, cap and vortex, centrifuge for $5 \mathrm{~min}$ at $2000 \times \mathrm{g}$, and carefully decant the supernatant (oil). Turn Falcon tube and place for 5 min onto a paper towel to drain remaining oil. 
Alternatively use Emulsion Collection Tray: place blue metal adaptor on the ePCR 96-well plate, then place the Emulsion Collection Tray like a cap (bottom up) on the top of the ePCR 96-well plate with metal adaptor. Use parafilm around metal adaptor to seal the connected plates, and flip the plates so that the ePCR plate is upside-down over the Emulsion Collection Tray. Centrifuge the plate construction for $2 \mathrm{~min}$ at $550 \times g$ (centrifuge with 96-well plate adaptor), place the assembly under a fume hood, remove the ePCR plate, and add $10 \mathrm{ml}$ of 2-butanol to the Collection Tray containing centrifuged ePCR emulsion. Pipette the mixture up and down until it appears homogeneous, transfer to a $50 \mathrm{ml}$ Falcon tube, and rinse reservoir with 2-butanol to collect remaining beads. Cap and vortex Falcon tube, centrifuge at $2000 \times \mathrm{g}$ for $5 \mathrm{~min}$, decant the oil phase and place inverted tube on paper towel, and then wait 5-10 min.

2. Wash templated beads: Resuspend the beads in $600 \mu \mathrm{l} \times$ Bead Wash Buffer, carefully pipet up and down and transfer beads to a fresh $1.5 \mathrm{ml}$ LoBind tube, rinse the remainder at the bottom of the $50 \mathrm{ml}$ Falcon tube with additional $600 \mu \mathrm{l} \mathrm{l} \times$ Bead Wash Buffer and transfer to $1.5 \mathrm{ml}$ LoBind tube, vortex, centrifuge at $21,000 \times g$ for $1 \mathrm{~min}$. Remove the oil phase with pipet, change pipet tip, discarding supernatant. Repeat bead washing as described but use $150 \mu \mathrm{l}$ to resuspend and transfer the beads, and $150 \mu \mathrm{l}$ to transfer remaining beads, add $\mathrm{l} \mathrm{ml} \mathrm{l} \times$ Bead Wash Buffer, centrifuge at $21,000 \times g$ for $1 \mathrm{~min}$, discard supernatant with pipet, resuspend in $200 \mu \mathrm{l} \times \mathrm{TEX}$ buffer, put tube on magnetic rack until it clears, discard supernatant, add $200 \mu \mathrm{l} \mathrm{l} \times \mathrm{TEX}$ buffer and sonicate the beads with program Declump l. Determine the bead concentration using a 1:10 dilution on an UV-spectrophotometer (NanoDrop), and compare the color of the bead dilution to photographed colors for different bead concentrations. Optimally, the concentration reflects closely the input amount of beads, about 1.6 billion, indicated by a "medium" color. Adjust the bead concentration by adding $1 \times$ TEX in case the color is too dark, or by placing tube in magnetic rack and removing small volume of supernatant in case the color is too light, to match the bead suspension to required volume. Quantify with NanoDrop.

3.4.3 Enrichment of Templated Beads
1. Prepare buffers and enrichment beads (from the SOLiD Bead Enrichment Kit) for use in subsequent steps: for a single ePCR reaction, transfer $1.8 \mathrm{ml}$ denaturing buffer into a $15 \mathrm{ml}$ Falcon tube, add $200 \mu \mathrm{l}$ denaturant, cap and vortex denaturing reagent. Prepare a fresh $60 \%$ glycerol solution, transfer $4 \mathrm{ml}$ $\mathrm{dH}_{2} \mathrm{O}$ into a $15 \mathrm{ml}$ Falcon tube and add $3 \mathrm{ml}$ glycerol twice, cap and vortex. For preparation of the enrichment beads, vortex the beads and immediately transfer $300 \mu$ of the beads to 
a new, $1.5 \mathrm{ml}$ LoBind tube, centrifuge for $5 \mathrm{~min}$ at $21,000 \times \mathrm{g}$, discard the supernatant, resuspend in $900 \mu \mathrm{l} \mathrm{l} \times$ Bind and Wash Buffer, centrifuge for $5 \mathrm{~min}$ at $21,000 \times g$, repeat Bind and Wash step, resuspend in $150 \mu \mathrm{l} 1 \times$ Bind and Wash Buffer, add $1.5 \mu \mathrm{l} \mathrm{lmM}$ Enrichment Oligo, vortex and place on a rotator at room temperature for $30 \mathrm{~min}$. Centrifuge beads for $5 \mathrm{~min}$ at $21,000 \times \mathrm{g}$, remove supernatant, resuspend in $900 \mu \mathrm{l}$ $1 \times$ TEX buffer, repeat centrifugation and TEX wash step, and resuspend beads in $75 \mu \mathrm{l} 1 \times$ Low Salt Binding Buffer.

2. Prepare templated beads for enrichment step: place tube with templated beads in magnetic rack, remove supernatant, resuspend in $300 \mu \mathrm{l}$ freshly prepared denaturing buffer, wait $\mathrm{l} \mathrm{min}$, place tube in magnetic rack, remove supernatant, repeat resuspension and magnetic rack step, resuspend templated beads in $300 \mu \mathrm{l} 1 \times$ TEX buffer, place in magnetic rack and remove supernatant, repeat resuspension in TEX and magnetic rack step. Resuspend the templated beads in $150 \mu \mathrm{TEX}$ and transfer to a new $0.5 \mathrm{ml}$ LoBind tube. Declump beads with Program 1 on Covaris.

3. Pipet enrichment beads (from step 1 ) into $0.5 \mathrm{ml}$ LoBind tube containing templated beads, vortex, spin down and sonicate the mixture using the Covalent Declump 3 program, pulse-spin and incubate at $61{ }^{\circ} \mathrm{C}$, vortex and spin down the mixture every $5 \mathrm{~min}$ over a time period of $15 \mathrm{~min}$. Cool beads on ice for $2 \mathrm{~min}$. Use a new $1.5 \mathrm{ml}$ LoBind tube and add $400 \mu \mathrm{l}$ of the $60 \%$ glycerol solution; do not vortex. Mix cooled beads by pipetting up and down, carefully load the total volume on the top of the glycerol-filled tube. Do not vortex at this point, but centrifuge for $3 \mathrm{~min}$ at $21,000 \times g$. Prepare a $2.0 \mathrm{ml}$ LoBind tube with $1 \mathrm{ml} 1 \times$ TEX buffer, and transfer top layer of beads (swimming on glycerol) to the bottom of tube prepared with TEX (be cautious to not transfer the un-templated beads sitting at the bottom of the glycerol tube). Fill up to $2.0 \mathrm{ml}$ with $1 \times$ TEX, vortex and centrifuge transferred templated beads at $21,000 \times g$ for $1 \mathrm{~min}$. If the beads are not sufficiently pelleted (in case of a carry-over of too much glycerol), divide them into two halves and fill each one into a tube, add $500 \mu \mathrm{l} 1 \times$ TEX buffer to each tube, vortex and centrifuge at $21,000 \times g$ for $1 \mathrm{~min}$. Discard supernatant, and add $200 \mu \mathrm{l} 1 \times$ TEX buffer to each tube. Resuspend the beads and pool the two halves again into one single tube. Otherwise, if the beads are pelleted, directly remove supernatant and add $400 \mu \mathrm{l} 1 \times$ TEX buffer. Proceed with protocol as follows: vortex and centrifuge tube at $21,000 \times g$ for $1 \mathrm{~min}$, remove supernatant, resuspend with $400 \mu \mathrm{l}$ Denaturing Buffer (which is prepared fresh by mixing $1.8 \mathrm{ml}$ Denaturation Buffer with $200 \mu \mathrm{l}$ Denaturant and vortexing), let stand for $1 \mathrm{~min}$, place 
in magnetic rack, remove supernatant, repeat denaturing and magnetic clarification until all white enrichment beads are removed. Resuspend in $400 \mu \mathrm{l} 1 \times \mathrm{TEX}$, place in magnetic rack, discard supernatant, repeat resuspension in TEX and magnetic rack step, resuspend templated beads in $200 \mu \mathrm{l} \mathrm{l} \times$ TEX, vortex, spin down and transfer into new $1.5 \mathrm{ml}$ LoBind tube. Declump beads using program Declump 1, place tube in magnetic rack, remove supernatant and resuspend in $400 \mu \mathrm{l}$ $1 \times$ TEX, place in magnetic rack, remove supernatant. Repeat the last two steps until supernatant is clear, and finally resuspend beads in $400 \mu \mathrm{l} 1 \times$ TEX (see Note 32$)$.

3.4.4 3'-End

Modification of Enriched Templated Beads

3.4.5 Bead Deposition on SOLiD Sequencing Slide and Instrument Run
The templates on the selected beads are subjected to a $3^{\prime}$-end modification to allow covalent bonding to the slide.

Sonicate enriched templated beads (see Subheading 3.4.3) with Declump 3, pulse-spin and prepare $500 \mu \mathrm{l} 1 \times$ Terminal Transferase Reaction (TTR) mix (from the SOLiD Bead Deposition Kit) per ePCR reaction. Mix $55 \mu \mathrm{l} 10 \times \mathrm{TTR}, 55 \mu \mathrm{l} 10 \times$ cobalt chloride, and $390 \mu \mathrm{dH}_{2} \mathrm{O}$ to a total volume of $500 \mu \mathrm{l}$. Prepare $1 \mathrm{mM}$ Bead Linker solution by mixing $1 \mu \mathrm{l}$ Bead Linker $(50 \mathrm{mM})$ to $49 \mu$ low TE buffer. Place the tube with enriched beads in magnetic rack, remove supernatant, resuspend in $100 \mu \mathrm{l} \mathrm{l} \times$ TTR buffer, and transfer reaction to a new $1.5 \mathrm{ml}$ LoBind tube. Place in magnetic rack, remove supernatant, repeat $\mathrm{I} \times \mathrm{TTR}$ resuspension and magnetic rack step, resuspend beads in $178 \mu \mathrm{l} \mathrm{l} \times \mathrm{TTR}$, and add $20 \mu \mathrm{l}$ Bead Linker solution ( $1 \mathrm{mM})$. Sonicate the mixture with Declump 3 , add $2 \mu \mathrm{l}$ Terminal Transferase enzyme $(20 \mathrm{U} / \mu \mathrm{l})$. Vortex, pulsespin, rotate tube for $2 \mathrm{~h}$ at $37^{\circ} \mathrm{C}$ (place rotator in incubator), then place tube in magnetic rack, discard supernatant, resuspend in $400 \mu \mathrm{l} \times \mathrm{TEX}$, perform magnetic clearing, resuspend in $200 \mu \mathrm{l} \times$ TEX. Quantify beads after utilizing program Declump 1 on NanoDrop and compare with SOLiD bead color chart.

1. Declump enriched templated beads with program Declump 1, pulse-spin, transfer appropriate volume of beads (as determined after NanoDrop quantification or in a WFA run) to a new $1.5 \mathrm{ml}$ LoBind tube, place in magnetic rack, remove supernatant, resuspend beads in $400 \mu$ l Deposition Buffer, vortex well, spin down, place in magnetic rack, discard supernatant. Repeat resuspension in Deposition Buffer and magnetic rack step twice according to the number of "fields" on the sequencing slide to be filled with beads; the beads need to be resuspended in different volumes, $300 \mu \mathrm{l}$ per well in a 8 -well deposition chamber, $400 \mu \mathrm{l}$ per well in a 4 -well, and $550 \mu \mathrm{l}$ per well in a single-well chamber.

2. Insert a sequencing slide into the slide carrier and place the assembled slide carrier into a deposition chamber base, and on top place the appropriate deposition chamber lid 


\subsection{Computational analysis of Fosmid Sequences and Haplotype Assembly}

\subsubsection{De-Indexing Barcoded Fosmid Pools}

3.5.2 NGS Read Alignment

3.5.3 Identification of Heterozygous Variants (1-well, 4-well, and 8-well). Sonicate beads with program Declump 3, pulse-spin and sonicate again with Declump 3, pipette the bead solution up and down, immediately fill bead solution into corresponding well of deposition chamber to avoid clumped beads on slide, seal portholes and incubate at $37^{\circ} \mathrm{C}$ for $1.5 \mathrm{~h}$.

3 . In the meantime, prepare the SOLiD sequencing instrument and set up SOLiD sequencing run as per manufacturer's protocol. After the incubation step has finished, remove adhesive seals, drain the top of the deposition chamber with Deposition Buffer, use a $1000 \mathrm{ml}$ pipette, press on portholes, and aspirate the entire Deposition Buffer from deposition wells until freshly layered Deposition Buffer is drawn into the wells, loosen lid of deposition chamber, immediately place the slide carrier assembly on the flow cell of the SOLiD instrument. Avoid drying out the slide, close flow cell, and proceed with the specific steps of the instrument run as described in the manufacturer's protocol.

The bioinformatics procedure starts from the raw reads obtained from barcoded high-throughput sequencing of each fosmid pool. The main steps include identification of heterozygous sites, fosmid detection, calling of fosmid-specific genotypes at heterozygous sites, and haplotype assembly using the predicted fosmids and their allele calls as virtual reads. Detailed steps to perform this procedure are summarized in Fig. 6 and described as follows:

Separate sequence reads per fosmid pool, identifying the barcode sequences in the first $5 \mathrm{bp}$ of each read. Reads sharing the same barcode belong to the same fosmid pool. For SOLiD reads, this is done using Bioscope 1.3. For Illumina reads, this can be done with the "Deconvolute" command of NGSEP.

Align the reads per pool against the reference genome. For SOLiD reads, use Bioscope 1.3. For reads sequenced using other platforms such as Illumina, align the reads using software tools for alignment of standard WGS reads such as bwa [17] or bowtie2 [14]. Then, sort the alignments by reference sequence and position using the sort command of samtools or the Picard software. In both platforms the final output of this step is a file in SAM or BAM format for each pool, containing the information of the reads aligned to the reference genome ( see Note 33 ).

Merge the BAM files obtained for each pool using the merge command of samtools or Picard. Then, identify variants against the reference genome, again using Bioscope 1.3 for SOLiD reads. Alternatively ( see Note 34), variants can be identified from aligned standard WGS read data by the use of the NGSEP pipeline [15], samtools [17], or the GATK pipeline [16] for other platforms such 


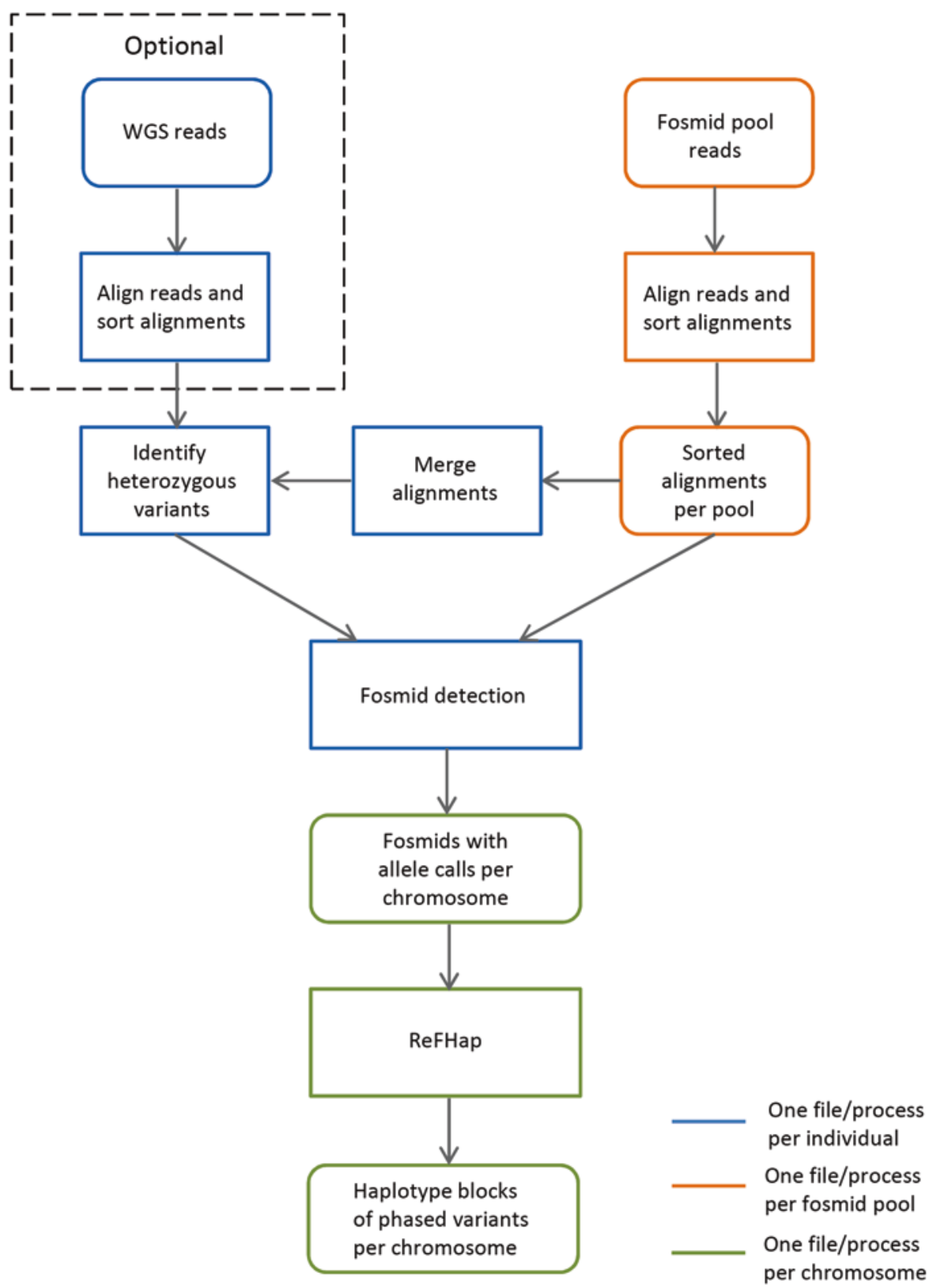

Fig. 6 Overview of computational steps involved in analysis of fosmid pool-based sequences and phasing. Complementary analyses of whole genome sequencing (WGS) data are presented as an option

as Illumina. Detailed instructions, scripts, and recommended parameters for command line usage of NGSEP can be found at (http://sourceforge.net/projects/ngsep/files/training/). Regardless of the sequencing platform and analysis pipeline used at this stage, the final output is a list of variants in VCF format and one sorted BAM file for each fosmid pool (see Note 35 ). 
Run the fosmid detection program following the specific instructions in the README file. This program receives the list of variants against the reference genome and an XML file describing, for each sequenced fosmid pool, the identification number (id), average coverage, and a path to the BAM file containing the aligned and sorted reads. A GFF file with the format produced by Bioscope 1.3 including predicted heterozygous deletions for the individual can be added as a parameter. If, moreover, files with allele calls in the same format are registered for each pool at the XML file, the fosmid detector can include these large deletions in the final haplotypes. With all this information, the fosmid detector performs the tasks described in detail earlier [3]. The following internal steps are being performed by the fosmid detector and summarized here:

(a) Extract the heterozygous variants from the VCF file obtained in the previous section.

(b) Predict the physical locations of the fosmids sequenced in each pool from the aligned reads of the pool and call one (usually homozygous) fosmid-specific genotype (FSG) for each heterozygous variant covered by one predicted fosmid. To predict fosmids, the software divides the genome in nonoverlapping segments of a fixed length ( $1 \mathrm{~kb}$ by default) and processes the alignments to calculate the read coverage of each segment. Then, it tags bins as candidate members for membership to a fosmid if the read coverage exceeds a minimum threshold $(0.4$ by default). Fosmids are called collecting nearly adjacent bins (with a maximum gap of 9 bins by default) extending between a minimum and a maximum threshold (by default 3-60 kb). Stretches that are longer than the maximum length are split into two or more predicted fosmids with lengths within the minimum and maximum thresholds. FSGs can be called either with NGSEP or with the allele coverage procedure described [3] (see Note 35). Although most FSGs should be homozygous, heterozygous FSGs are possible if two fosmids from the two parental homologues of a chromosome overlap within one pool. Consequently, bins showing heterozygous calls within a pool are tagged, and the tagged fosmids split into two fosmids, the first predicted from the covered bins extending upstream of the first tagged bin, and the second from the covered bins following the last tagged bin. This step is important to avoid switch errors produced by overlaps of complementary fosmids. After these steps, fosmids containing only one homozygous FSG are removed to obtain the set that will be used for single individual haplotyping.

(c) Finally, the fosmid detector allows generation of the input matrix for phasing separately for each chromosome, with the fosmids (one per row) sorted by the position of the first genotyped variant, and the allele calls (one per column) designated 
by physical genome position. This procedure results in the production of the variation matrixes that serve as input files for haplotype assembly by use of ReFHap.

\subsubsection{Phasing by Use} of ReFHap
For each chromosome, take the input file for ReFHap generated by the fosmid detector as described above (4c) and run ReFHap following the instructions available in the README file. Details of the algorithms implemented in ReFHap are available in Duitama et al., 2010 [11], and benchmarks with other tools/SIH algorithms can be found in Duitama et al., 2011 [5]. For each chromosome, ReFHap outputs the blocks of variants that could be phased by tiling the fosmids (see Fig. 7a), and for each block, it outputs the chromosomal position of each phased variant, followed by the allele in the first haplotype, and the allele in the second haplotype (see Fig. 7b).

\begin{tabular}{|c|c|c|c|c|c|c|c|}
\hline chr1 & isseq & ctg & 1 & 40999 & 1 & + & id=chr1_BC26_6958:posn=1-40999:reads=970:bins=40:cov=0.99:poolld=BC26 \\
\hline chr1 & FosSeq & ctg & 1 & 30999 & 1 & + & id=chr1_BC28_10738:posn=1-30999:reads=482:bins $=30: C$ \\
\hline chr1 & FosSeq & ctg & 1 & 52999 & 1 & + & id=chr1_BC29_12761:posn=1-52999:reads=3026:bins $=52:$ cov $=2.41$ :poolld $=B C 29$ \\
\hline chr1 & FosSeq & ctg & 1 & 54999 & 1 & + & 1260:Dins $=54$ : \\
\hline chr1 & FosSeq & ctg & 1 & 30999 & 1 & + & id $=$ chr1_B22_44150:posn $=1-30999:$ reads $=685:$ bins $=30:$ cov $=1.05:$ poolld $=B 22$ \\
\hline chr1 & FosSeq & ctg & 1 & 59999 & 1 & + & id=chr1_B23_45772:posn=1-59999:reads=1376:bins $=59: c 0 v$ \\
\hline chr1 & FosSeq & ctg & 1 & 25999 & 1 & + & $\mathrm{sn}=1-25999:$ reads $=423:$ bins $=25: c$ \\
\hline chr1 & Fosseq & ctg & 1 & 55999 & 1 & + & id $=$ chr1_B28_53864:posn=1-55999:reads $=1915:$ bins $=55:$ cov=1.64:poolld $=828$ \\
\hline chr1 & FosSeq & ctg & 1 & 38999 & 1 & + & r1_B30_57409:p \\
\hline chr1 & FosSeq & ctg & 1 & 45999 & 1 & + & $=1-45999: \mathrm{re}$ \\
\hline chr1 & FosSeq & ctg & 1 & 29999 & 1 & + & id=chr1_B37_68417:posn=1-29999:reads=995:bins $=29:$ cov $=1.54:$ poolld $=837$ \\
\hline ar 1 & $\mathbf{F}$ & ctg & 1 & 199 & 1 & + & (2) \\
\hline chr1 & FosSeq & ctg & 1 & 39999 & 1 & + & id=chr1_B40_73387:posn=1-39999:reads=1677:bins $=39: c 0 v=1.96:$ poolld $=B 40$ \\
\hline chr1 & FosSeq & ctg & 1000 & 42999 & 1 & + & id $=$ chr1_BC22_1785:posn $=1000-42999:$ reads $=635:$ bins $=42:$ cov $=0.63$ :poolld $=B C 22$ \\
\hline chr1 & FosSeq & ctg & 1000 & 38999 & 1 & + & 1_B13_31958:posn=1000-38999:reads $=521$ :bins $=38:$ cov $=0.66:$ poolld $=813$ \\
\hline chr1 & FosSeq & ctg & 1000 & 28999 & 1 & + & id=chr1_B19_40285:posn=1000-28999:reads=528:bins=28:cov=0.89:poolld=B19 \\
\hline chr1 & FosSeq & ctg & 1000 & 29999 & 1 & + & id=chr1_B29_55605:posn=1000-29999:reads=576:bins=29:cov=0.96:poolld=B29 \\
\hline chr1 & FosSeq & ctg & 1000 & 27999 & 1 & $\operatorname{tac}>0$ & id=chr1_B33_61712:posn=1000-27999:reads=345:bins $=27:$ cov=0.59:poolld $=833$ \\
\hline chr1 & FosSeq & ctg & 1000 & 53999 & 1 & + & B36_66810:posn=1000-53999:reads=1522: bins $=53:$ cov=1.34:poolld $=836$ \\
\hline chr1 & FosSeq & ctg & 1000 & 10999 & 1 & +1 & ads=139:bins=10:cov=0.64:poolid $=838$ \\
\hline chr1 & $\mathrm{Fc}$ & ctg & 2000 & 9 & & & id=chr1_BC30_15089:posn=2000-28999:reads=324:bins=27:cov=0.5:poolld: \\
\hline Cnir & FosSeq & ctg & 4000 & 22999 & 1 & & id=chr1_BC27_8937:posn=4000-22999:reads=132:bins=19:cov=0.29:poolid=BC27 \\
\hline chr1 & FosSeq & ctg & 4000 & 29999 & 1 & & id=chr1_B25_48983:posn=4000-29999:reads $=205:$ bins $=26: c o v=0.36:$ poolld $=825$ \\
\hline chr1 & FosSeq & ctg & 6000 & 56999 & 1 & & id=chr1_B14_33493:posn=6000-56999:reads=983:bins=51:cov=0.93:poolid=B14 \\
\hline
\end{tabular}

\begin{tabular}{|ccc|}
\hline BLOCK: offset: 2 len: 2 phased: $\mathbf{2}$ \\
\hline $\mathbf{5 3 6 6 0 2}$ & 0 & 1 \\
\hline $\mathbf{5 5 6 6 5 5}$ & 1 & 0 \\
$\mathbf{* * * * * * *}$ & & \\
BLOCK: offset: 4 len: 231 phased:225 \\
$\mathbf{7 1 5 8 8 7}$ & 1 & 0 \\
$\mathbf{7 1 6 5 9 5}$ & 1 & 0 \\
$\mathbf{7 2 4 4 2 9}$ & 1 & 0 \\
$\mathbf{7 4 7 7 9 9}$ & 0 & 1 \\
$\mathbf{7 4 7 9 1 1}$ & 1 & 0 \\
$\mathbf{7 4 8 3 0 0}$ & 1 & 0 \\
$\mathbf{7 4 8 3 3 1}$ & 1 & 0 \\
$\mathbf{7 6 6 4 0 9}$ & 0 & 1 \\
$\mathbf{7 7 9 7 1 4}$ & 1 & 0 \\
$\mathbf{7 7 9 7 3 7}$ & 1 & 0 \\
$\mathbf{7 8 0 5 5 9}$ & 1 & 0 \\
$\mathbf{7 8 6 9 0 2}$ & 1 & 0 \\
$\mathbf{8 0 4 5 3 1}$ & 1 & 0 \\
$\mathbf{8 0 5 2 8 4}$ & 0 & 1 \\
$\mathbf{8 0 5 3 8 6}$ & 1 & 0 \\
$\mathbf{8 0 5 4 1 9}$ & 1 & 0 \\
$\mathbf{8 0 5 5 5 8}$ & 1 & 0 \\
$\mathbf{8 0 5 5 9 1}$ & 0 & 1 \\
$\mathbf{8 0 5 8 9 2}$ & 1 & 0 \\
$\mathbf{8 0 5 8 9 7}$ & 1 & 0 \\
$\mathbf{8 0 5 8 9 8}$ & 1 & 0 \\
$\mathbf{8 0 5 9 0 5}$ & 0 & 1 \\
$\mathbf{8 0 5 8 9 7}$ & 1 & 0 \\
$\ldots$ & & \\
\hline
\end{tabular}

Fig. 7 Examples of phasing output files. (a) Output file fosmid contigs. A part of a typical output file is shown, listing per chromosome the detected contigs as an output of the fosmid detection program (see Subheading 3.5.4). The chromosomal start and end positions per contig are given in columns 4 and 5 by indicating the specific bins (first and last) as intervals of fixed length (1000 bp) that are covered by the fosmid contig. In the following columns, additional properties such as number of reads, bins, read coverage and fosmid super-pool identification number are shown. (b) Output file ReFHap with phased variants. A part of a typical output file is shown, listing the haplotype blocks per chromosome with the numbers of phased variants per block. In the first column from the left, the chromosomal position numbers of heterozygous variants are given, and in the adjacent, second and third columns the two haplotypes, with the variant alleles (different from the reference sequence) denoted by " 1 " and the reference alleles denoted by " 0. " Thus, the second column shows the specific combinations of variants from top to bottom for "Haplotype 1" and the third column the specific combinations of variants constituting "Haplotype 2" 


\section{Notes}

1. Optimally, one kit would be sufficient to generate ten individual fosmid libraries. In practice, the kit will allow generating three to four libraries.

2. Do not vortex the sample to avoid shearing the HMW gDNA.

3. Do not transfer any flocculent material.

4. We find that the gDNA cannot be resuspended in buffer, if the alcohol is not completely evaporated.

5. Alternatively, the Tube Rotisserie Rotator (VWR) can be used, which is also employed during SOLiD sequencing library preparation.

6. Alternatively run a large $1 \%$ agarose gel of at least $20 \mathrm{~cm}$ length to allow for sufficient resolution, at $30 \mathrm{~V} / \mathrm{cm}$ overnight.

7. Since under conditions of manual shearing, i.e., variable pressure and speed, the shearing results will turn out to a certain extent variable, check the results on an agarose gel of at least $20 \mathrm{~cm}$ length overnight. In order to standardize our manual shearing procedure (which we used at the outset), we constructed an automated prototype, which is not generally available. Therefore, collecting information from experts in the field $[18,19]$, we have chosen to refer to commercially available HydroShear devices here and the settings that have been experimentally verified.

8. Avoid unnecessary pipetting or vortexing after end-repair, pipet carefully and gently to avoid mechanical damage.

9. If no preparative comb is available, tape 2 wells of a $1.5 \mathrm{~mm}$ thick 20-well comb together, keep one well to each side of sample empty, first and last well are used for size ladder. The slots of the preparative comb have a volume of about $200 \mu \mathrm{l}$.

10. The gel is very fragile, therefore, do not lift the gel, but transfer it on the gel tray of the electrophoresis chamber.

11. Sheared gDNA appears as a smear; try to cut out gel pieces as exactly as possible to minimize subsequent gelase digestion. Do not stain the gel with ethidium bromide and avoid UVB illumination, which will damage the DNA and significantly reduce ligation efficiency.

12. Scrape glycerol stock of EPII00 bacteria with heat sterilized inoculating loop only briefly before streaking over agar plate to ensure growth of single colonies.

13. Prepare Epil00 bacteria for mass infection 2 days before advancing to the phage packaging step. 
14. In order to evaporate condensed water due to storage, place the agar plates in a laminar flow bench one hour before use, remove the cover plates, and let them dry.

15. It is recommendable to produce a total of $1.5 \times 10^{6}$ phages to have a bit of excess later during the fosmid clone partitioning step.

16. The amplification of fosmid clones to high numbers in liquid culture can introduce preferential amplification, that is, overgrowth of few fosmid clones in a fosmid pool, and may lead to significant library complexity reduction. Our experimental results have shown, however, that this was only the case if the second amplification step, required to generate sufficient copies of the $\sim 15,000$ fosmid clones in a super-pool before isolation of fosmid DNA for NGS, was also made in liquid cultures. In that case, library complexity was substantially reduced. If the second required amplification step was, however, performed using agar plates, both haploid genomes were found to be nearly completely represented, with an equal physical coverage of both haplotypes. Specifically, we have performed high-throughput SNP typing of the $4 \mathrm{Mb} \mathrm{MHC}$ region in one 96-well plate of the fosmid pool-formatted library, demonstrating presence of $\mathrm{MHC}$ fosmid clones according to expectations in the fosmid pools and nearly complete and equal coverage of both MHC haplotypes.

17. The wet-lab-based removal of Epi 100 genomic DNA is only partially sufficient; the remaining Epil00 genome, as evident in NGS reads, needs to be removed computationally.

18. Make sure to check whether the tubes are suitable to withstand the centrifugal forces.

19. Use 51 bottles with cooled, distilled water stored at $4{ }^{\circ} \mathrm{C}$ to be able to start the Covaris system more quickly.

20. To prepare a $4 \%$ agarose gel, mix buffer and agarose, let ingredients stand overnight, heat the agarose carefully in microwave, avoid over-boil by checking every $2 \mathrm{~s}$.

21. The E-Gel Size Selection Gel or Flash Gel Recovery System can be used instead; in our experience the recovery was not superior to the gel-based size selection.

22. We created 48 different barcode tags within the Pl-Adaptor sequence (which we shortened) before SOLiD barcoded adaptors became commercially available. Thus, 48 pools /sequencing libraries could be parallel processed, and up to 16 barcoded NGS libraries could be multiplexed later in a single sequencing run. To avoid color imbalances on the SOLiD NGS system, all 16 barcoded adaptors should also be employed (per run) in the case where the number of samples is smaller. 


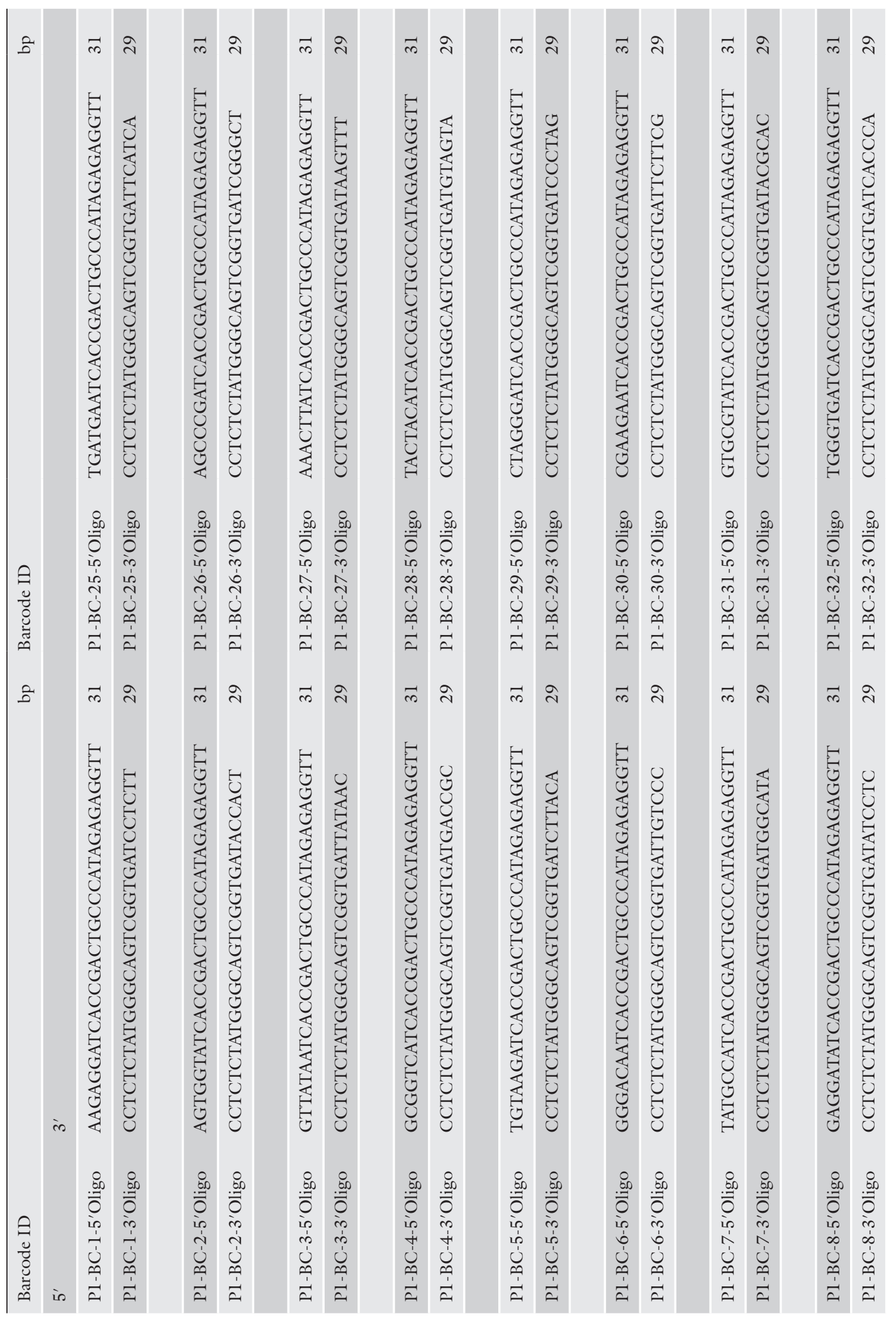




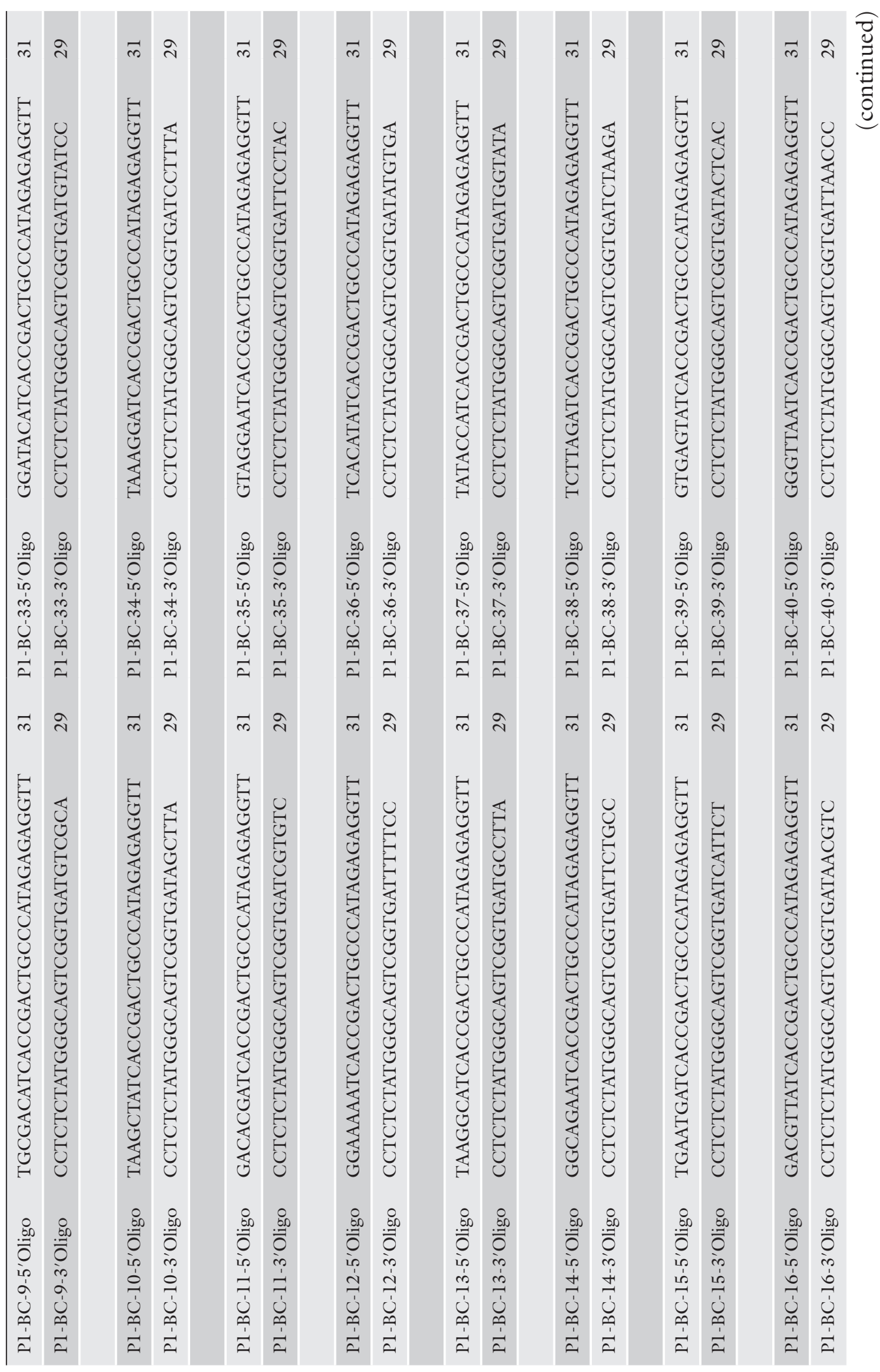




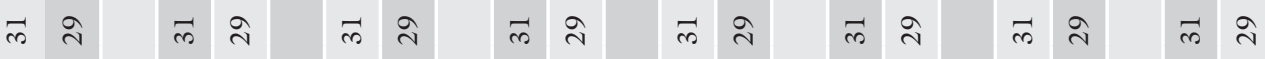

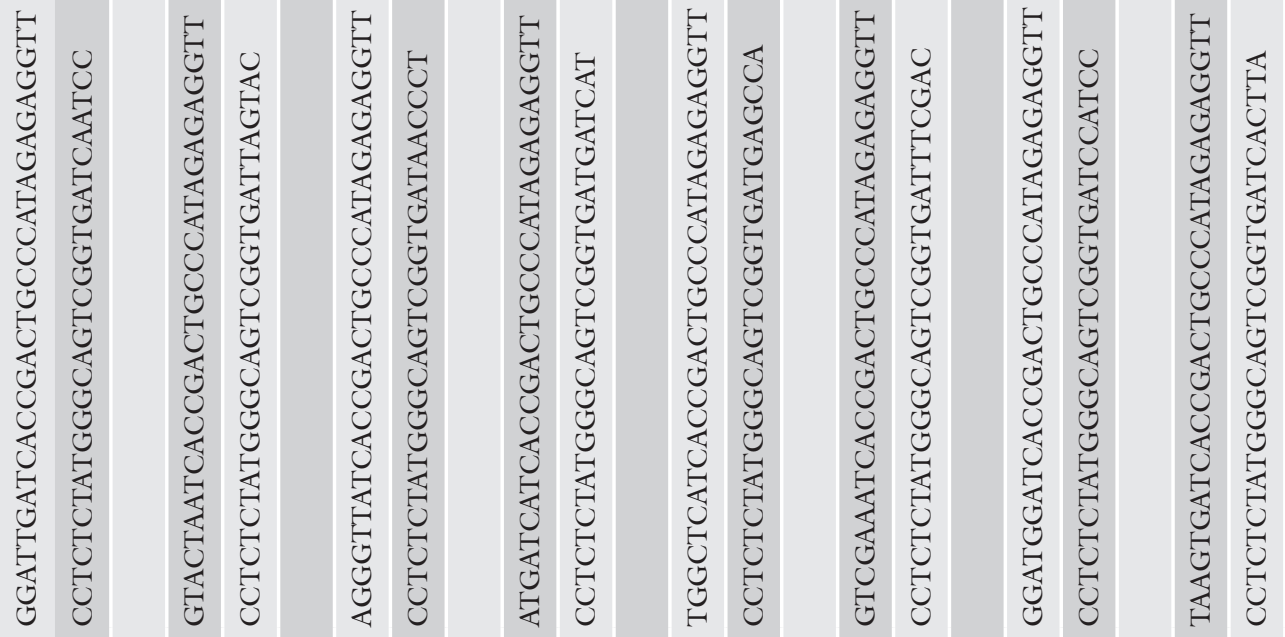

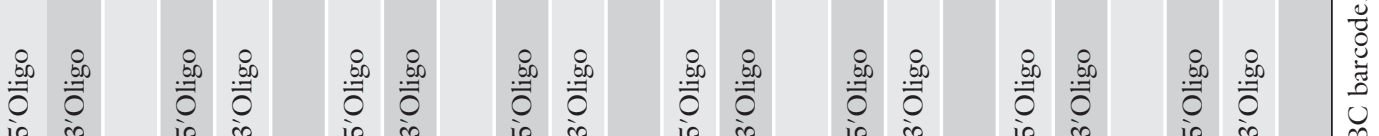

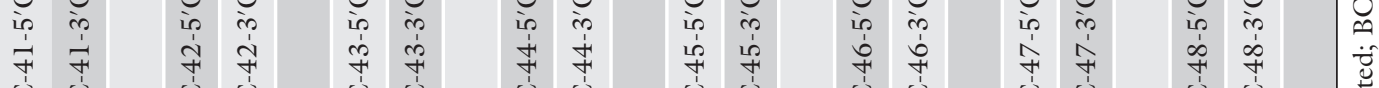

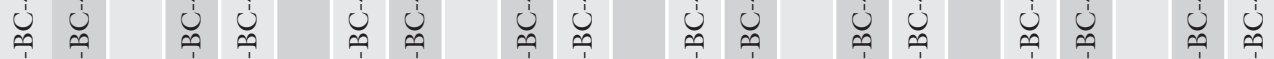

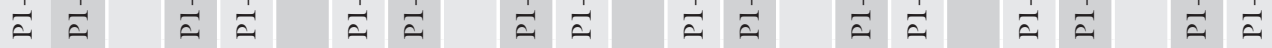

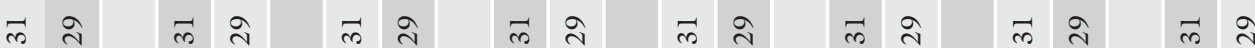

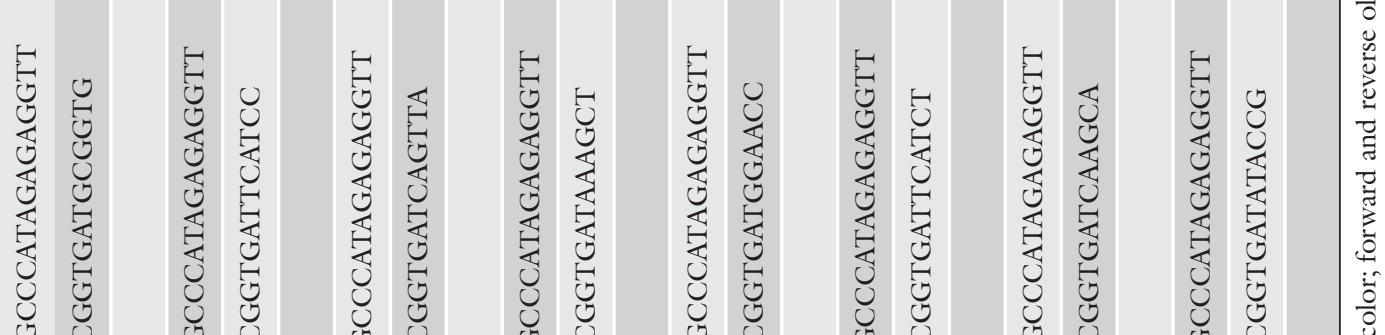

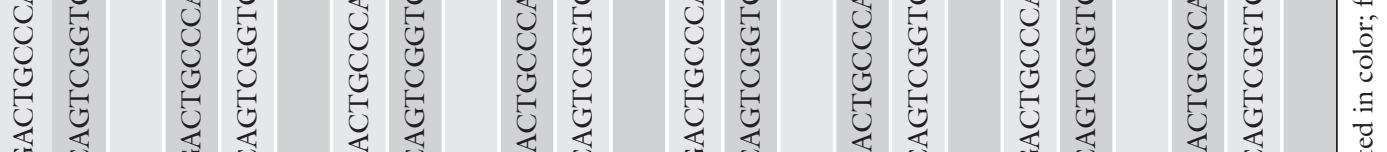

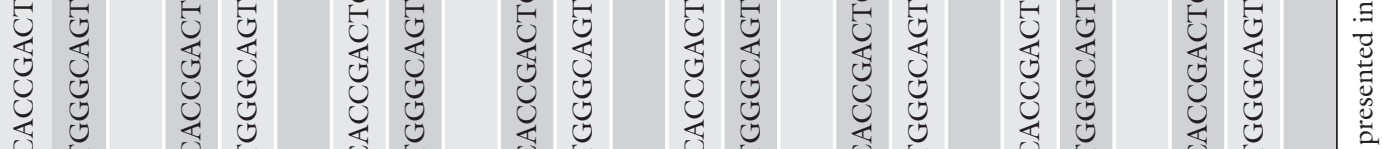

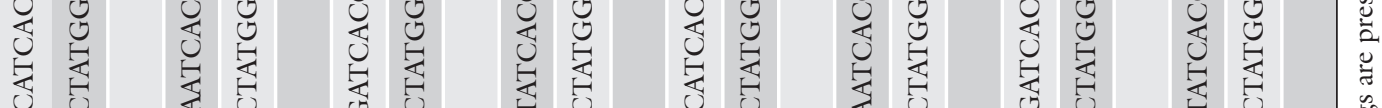

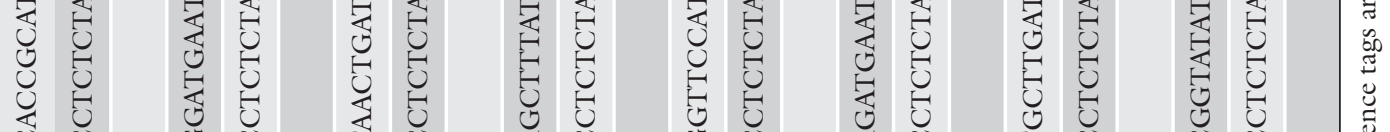
出

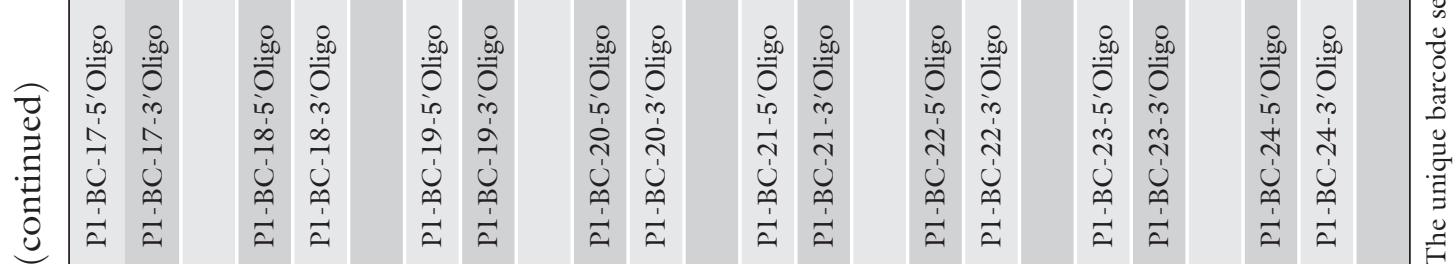


23. Alternatively use AMPure Beads to size-select and purify adaptor-ligated DNA fragments as described in the SOLiD User Manual. In our experience, the FlashGel Recovery System (Lonza) and E-Gel SizeSelect system (Thermo Fisher Scientific) did not work as efficiently as the manual gel-based size selection.

24. Do not heat-dissolve the gel as recommended in the manufacturer's protocol to protect the DNA from denaturation and heteroduplex formation.

25. It would be possible to cut out the vector sequence with NotI first, and to recover insert DNA with a gel-based size selection.

26. To avoid chimerism, the DNA concentration should be low and the reaction volume high enough to increase the chances that ligation will occur between the two ends of one DNA molecule, rather than two different DNA molecules.

27. DNA polymerase I activity is highly temperature-sensitive, chilled reagents and ice bathing are crucial to create optimal tag length. Thus, a higher temperature, or increased incubation time, may lead to an extension of the size of the fragments.

28. Consistent with the SOLiD sequencing protocol, barcoded adaptors for mate-paired sequencing were not established at the time.

29. Use differently colored caps, if several fosmid pool DNA samples are processed.

30. Run as few cycles as necessary to achieve visible gel bands; over-amplification can lead to redundant library molecules and reduces the library complexity. Start with 5 cycles, if DNA concentration is about $400 \mathrm{ng} / \mu \mathrm{l}$, start with up to 8 cycles, if DNA concentration is about $50 \mathrm{ng} / \mu \mathrm{l}$. If necessary, pause PCR reaction and check an aliquot on a gel before running additional PCR cycles.

31. For paired-end libraries, the final concentration needs to be $50 \mathrm{pg} / \mu \mathrm{l}$ and for mate-paired libraries, the final concentration needs to be $96 \mathrm{pg} / \mu \mathrm{l}$ to correspond to $500 \mathrm{pM}$.

32. Do not magnet the $\mathrm{P} 2$-enriched beads before denaturing buffer has been added.

33. The use of the standard SAM or BAM format at this step, as well as the VCF format at the next step, is helpful to achieve independence from the sequencing platform for fosmid detection and haplotyping.

34. The identification of variants against the reference genome can be achieved directly from fosmid pool NGS and analysis by merging the BAM files from each pool as described here, or, alternatively, by analysis of WGS data, in the case where WGS is performed in complementation to fosmid pool NGS, see also Fig. 6. 
35. In the latter case, if $\mathrm{nl}$ and $\mathrm{n} 2$ are the largest and second largest allele coverage, respectively, and $t \mathrm{l}$ and $\mathrm{t} 2$ are two corresponding minimum thresholds (with defaults 1 and 2, respectively), a homozygous FSG is called if $\mathrm{nl} \geq \mathrm{tl}$ and either $\mathrm{n} 2<\mathrm{t} 2$ or $\mathrm{nl} \geq 2 \times \mathrm{n} 2$. If the first condition does not hold, the FSG is left uncalled. If the second condition does not hold, a heterozygous FSG is called.

\section{References}

1. Hoehe MR (2003) Haplotypes and the systematic analysis of genetic variation in genes and genomes. Pharmacogenomics 4:547-570. doi:10.1517/phgs.4.5.547.23791

2. Tewhey R, Bansal V, Torkamani A, Topol EJ, Schork NJ (2011) The importance of phase information for human genomics. Nat Rev Genet 12:215-223. doi:10.1038/nrg2950

3. Suk EK, McEwen GK, Duitama J, Nowick K, Schulz S, Palczewski S, Schreiber S, Holloway DT, McLaughlin S, Peckham H et al (2011) A comprehensively molecular haplotype-resolved genome of a European individual. Genome Res 21:1672-1685. doi:10.1101/gr.125047.111

4. Kitzman JO, Mackenzie AP, Adey A, Hiatt JB, Patwardhan RP, Sudmant PH, Ng SB, Alkan C, Qiu R, Eichler EE et al (2011) Haplotyperesolved genome sequencing of a Gujarati Indian individual. Nat Biotechnol 29:59-63. doi:10.1038/nbt.1740, nbt.1740 [pii]

5. Duitama J, McEwen GK, Huebsch T, Palczewski S, Schulz S, Verstrepen K, Suk EK, Hoehe MR (2012) Fosmid-based whole genome haplotyping of a HapMap trio child: evaluation of single individual haplotyping techniques. Nucleic Acids Res 40:2041-2053. doi:10.1093/Nar/Gkr1042

6. Peters BA, Kermani BG, Sparks AB, Alferov O, Hong P, Alexeev A, Jiang Y, Dahl F, Tang YT, Haas J et al (2012) Accurate whole-genome sequencing and haplotyping from 10 to 20 human cells. Nature 487:190-195. doi:10.1038/ naturel1236

7. Kaper F, Swamy S, Klotzle B, Munchel S, Cottrell J, Bibikova M, Chuang HY, Kruglyak S, Ronaghi M, Eberle MA et al (2013) Whole-genome haplotyping by dilution, amplification, and sequencing. Proc Natl Acad Sci U S A 110:5552-5557. doi:10.1073/pnas.1218696110

8. Lo C, Liu R, Lee J, Robasky K, Byrne S, Lucchesi C, Aach J, Church G, Bafna V, Zhang $\mathrm{K}$ (2013) On the design of clone-based haplotyping. Genome Biol 14:R100. doi:10.1186/ gb-2013-14-9-r100

9. Hoehe MR, Church GM, Lehrach H, Kroslak T, Palczewski S, Nowick K, Schulz S, Suk EK,
Huebsch T (2014) Multiple haplotype-resolved genomes reveal population patterns of gene and protein diplotypes. Nat Commun. 2014 Nov 26;5:5569. doi: 10.1038/ncomms6569

10. Burgtorf C, Kepper P, Hoehe M, Schmitt C, Reinhardt R, Lehrach H, Sauer S (2003) Clone-based systematic haplotyping $(\mathrm{CSH})$ : a procedure for physical haplotyping of whole genomes. Genome Res 13:2717-2724. doi:10.1101/Gr.1442303

11. Duitama J, Huebsch T, McEwen G, Suk E-K, Hoehe MR (2010) ReFHap: a reliable and fast algorithm for single individual haplotyping. Proceedings of the first ACM international conference on bioinformatics and computational biology ACM, Niagara Falls, New York, pp. 160-169

12. 1000 Genomes Project Consortium, Auton A, Brooks LD, Durbin RM, Garrison EP, Kang HM, Korbel JO, Marchini JL, McCarthy S, McVean GA et al (2015) A global reference for human genetic variation. Nature 526:68-74. doi:10.1038/nature 15393

13. Li H, Durbin R (2009) Fast and accurate short read alignment with Burrows-Wheeler transform. Bioinformatics 25:1754-1760. doi:10.1093/bioinformatics/btp324

14. Langmead B, Salzberg SL (2012) Fast gappedread alignment with bowtie 2 . Nat Methods 9:357-359. doi:10.1038/nmeth.1923

15. Duitama J, Quintero JC, Cruz DF, Quintero C, Hubmann G, Foulquie-Moreno MR, Verstrepen KJ, Thevelein JM, Tohme J (2014) An integrated framework for discovery and genotyping of genomic variants from highthroughput sequencing experiments. Nucleic Acids Res 42:e44. doi:10.1093/nar/gktl381

16. DePristo MA, Banks E, Poplin R, Garimella KV, Maguire JR, Hartl C, Philippakis AA, del Angel G, Rivas MA, Hanna M et al (2011) A framework for variation discovery and genotyping using next-generation DNA sequencing data. Nat Genet 43:491-498. doi:10.1038/ng.806

17. Li H (2011) A statistical framework for SNP calling, mutation discovery, association mapping and population genetical parameter 
estimation from sequencing data. Bioinformatics 27:2987-2993. doi:10.1093/bioinformatics/btr509

18. Nedelkova M, Maresca M, Fu J, Rostovskaya M, Chenna R, Thiede C, Anastassiadis K, Sarov M, Stewart AF (2011) Targeted isolation of cloned genomic regions by recom- bineering for haplotype phasing and isogenic targeting. Nucleic Acids Res 39:el37. doi:10.1093/nar/gkr668

19. Donahue WF, Ebling HM (2007) Fosmid libraries for genomic structural variation detection. Curr Protoc Hum Genet Chapter 5:Unit 5.20. doi:10.1002/0471142905.hg0520s54 